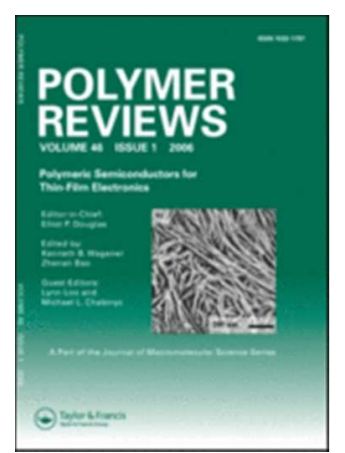

\title{
Poloxamers for surface modification of hydrophobic drug carriers and their effects on drug delivery
}

\begin{tabular}{|r|l|}
\hline Journal: & Polymer Reviews \\
\hline Manuscript ID: & LMSC-2013-0215.R2 \\
\hline Manuscript Type: & Review \\
\hline Date Submitted by the Author: & n/a \\
\hline Complete List of Authors: & $\begin{array}{l}\text { Shubhra, Quazi T. H.; University of Pannonia, Research Institute of } \\
\text { Chemical and Process Engineering } \\
\text { Feczkó, Tivadar; Research Institute of Chemical and Process Engineering, } \\
\text { Tóth, Judit; Research Institute of Chemical and Process Engineering, } \\
\text { Gyenis, János; Research Institute of Chemical and Process Engineering, }\end{array}$ \\
\hline Keywords: & poloxamer , surface modification, drug release \\
\hline & \\
\hline
\end{tabular}

\section{SCHOLARONE ${ }^{\text {Ix }}$}

Manuscripts 


\title{
Poloxamers for surface modification of hydrophobic drug carriers and their effects on drug delivery
}

\author{
Quazi T. H. Shubhra ${ }^{a, b^{*}}$, Tivadar Feczkó ${ }^{b, c}$, Judit Tóth $^{\text {b,c }}$, János Gyenis ${ }^{b}$ \\ ${ }^{a}$ Doctoral School of Molecular and Nanotechnologies, Faculty of Information \\ Technology, University of Pannonia, Egyetem u.10, H-8200 Veszprém, Hungary, \\ ${ }^{b}$ Research Institute of Chemical and Process Engineering, Faculty of Information \\ Technology, University of Pannonia, Egyetem u.10, H-8200 Veszprém, Hungary, \\ ${ }^{c}$ Institute of Materials and Environmental Chemistry, Research Centre for Natural \\ Sciences, Hungarian Academy of Sciences, Pusztaszeri u. 59-67., H-1025Budapest,
}

\section{Hungary}

\begin{abstract}
Tri-block copolymer poloxamers are successfully employed for reducing adsorption of proteinous molecules onto hydrophobic surfaces, which will protect them from quick engulfing by macrophages. For sustained systemic circulation of hydrophobic drug carriers, particle surfaces need suitable modification for avoiding phagocytosis and this can be successfully done by poloxamers. They can affect the drug release profile, which makes them a very promising agent for targeted delivery. This review discusses the structure, characteristics and advantages of poloxamers. Poloxamer adsorption onto hydrophobic surfaces and adlayer thickness, relative phagocytic uptake and drug release profiles of coated drug loaded particles have been described in detail.
\end{abstract}

Keywords: poloxamer; micelle; drug release; surface modification; nanoparticles; microparticles. 
*Correspondance: shubhro.du@gmail.com; Fax:+36-88624038 ; Tel : +36204843689.

\section{Introduction}

Since 1980s, scientists have been trying to develop potent drug carriers. The primary cause behind tremendous development of medical industry is recognizing essentiality for developing current therapies for drugs already marketed and yet to be marketed. Drugs face tremendous hindrance inside the human body that needs to get over so that they can arrive at the target site(s). If they fail to reach, they cannot execute their biological function(s). The plasma proteins of our body adsorb exogenous particles which is very significant part of defense mechanism of the human body ${ }^{1,2,3}$. Our body clears foreign materials with the help of MPS ${ }^{4,5,6,7,8,9}$. Non-ionic surfactants are now in widespread applications in the pharmaceutical sciences for the coating of surfaces to facilitate drug targeting. Sustainable circulation can be obtained by proper modification of hydrophobic NPs and MPs which will help them fending off phagocytosis ${ }^{10}$. Poloxamers are block copolymers ${ }^{11,12,13,14}$. They have hydrophilic ethyleneoxide (EO) and hydrophobic propyleneoxide (PO) units. Polymer chain PEO and PPO blocks form A-B-A type structure. This structure helps them showing surfactant characters. They also have the capability of interacting with hydrophobic particles, biological membranes, etc. $^{15,16,17}$.

Several reviews have been published in the last decade on the application of poloxamers for drug delivery ${ }^{18,19}$. Kabanov et al. in $2002^{20}$ also reviewed drug and gene delivery, and described poloxamer micelles and micellar drug formulations, drug release from micelles and pharmacokinetic and biodistribution of poloxamers. Brain and oral bioavailability of poloxamer was also discussed. In 2008, Batrakova et al. published a 
review on drugs and genes delivery using poloxamers ${ }^{21}$. Micellar formulations and unimer-associated biological response modifying effects of poloxamers were described in that study showing exceptional potentiality of application in pharmaceutical industries. Multiple effects of poloxamers in multidrug resistance (MDR) cells were also highlighted. To the best of our knowledge, no reviews have been published focusing on surface modification of hydrophobic drug carriers, adsorption isotherm, adlayer thickness and drug delivery profile of poloxamer coated hydrophobic drug carriers.

\section{Structure and characteristics of poloxamers}

Poloxamer (also known as "Pluronic") is a triblock amphiphilic copolymer of EO and PO. The simplest structure is: $(\mathrm{EO})_{\mathrm{x}}-(\mathrm{PO})_{\mathrm{y}}-(\mathrm{EO})_{\mathrm{x}}$ (Figure 1). Unit number in poloxamers (e.g. $\mathrm{x}$ and y) can be varied.

Poloxamer synthesis is simple and can be done by adding monomers sequentially. Preferred catalyst is alkaline type e.g. $\mathrm{KOH}, \mathrm{NaOH}$, etc. ${ }^{22}$. Initiation step is the polymerization of the PO block. After that PEO chains grow on the two sides of PPO chain. Table 1 shows characteristics of some poloxamers of BASF Corporation, which have been discussed in this review. Poloxamers having various EO (x) and PO units (y) are characterized by their own HLB ( hydrophilic-lipophilic balance) ${ }^{23}$.

The most important benefits of these compounds in surface modification of drug carrier particles are:

(1) They have amphiphilic structures and show surfactant behavior. So, it is possible to improve hydrophobic surface's solubility in aqueous solution. The miscibility of the substances having various hydrophobicities can also be improved. The control of various 
amphiphilic property is possible with controlled use of blocks length (structural control) and temperature 24,25 .

(2) These compounds have low toxicity and lack of immunogenic activity ${ }^{26,27,28}$.

(3) They can affect the drug release profile, which makes them very potent constituents existing in the field of controlled drug delivery.

(4) In water, above critical micelle concentration (CMC) and temperature (CMT), poloxamer micelle formation is observed ${ }^{29}, 30,31,32,33$. Poloxamer micelles are potential carriers of different types of drugs.

Poloxamers have much more advantageous applications that are not being mentioned here, since they are not relevant to the area of our review.

\section{Micellization}

Individual molecules (also known as 'unimers') of amphiphilic block copolymers generally have the tendency of being assembled to different micellear conformation in water when the concentration is higher than CMC. This process is known as 'micellization' $34,35,36$. Simplest definition of CMC is concentration at which micelle formation takes place. Poloxamer's CMC is highly dependent on the length of its two block. Increase in PPO chain length elevates the overall hydrophobicity. It leads to the segregation of PPO chains inside the micelle core $37,38,39$. Consequently, the CMC decreases with the increase in PPO chain length ${ }^{40}$. Conversely, increasing PEO block length will reduce core hydrophobicity destabilizing the micelle. Therefore, enhancement of PEO block length will increase the $\mathrm{CMC}^{40,41}$. 
Common methods used for determining CMC of poloxamers are: viscosimetry ${ }^{42}$, surface tension measurements ${ }^{43}$, chromatographic analysis $^{44}$, small angle neutron scattering $(\mathrm{SANS})^{45}$, small angle X-ray scattering $(\mathrm{SAXS})^{46}$, light scattering $^{47}$, differential scanning calorimetry ${ }^{48}$, acoustic measurements ${ }^{49}$, etc. Typically, poloxamers that are used to deliver different drugs possess CMC in the range $1 \mu \mathrm{M}-1 \mathrm{mM}^{20}$.

The usual diameter for poloxamer micelles ranges between $10 \mathrm{~nm}$ and $200 \mathrm{~nm}^{50}$. Micelles can have different shapes: sphere, rod, lamellar, etc. The micelle shapes mainly depend on the length of the PEO and PPO chains. Concentration of poloxamer and temperature also play significant role in the formation of different shapes. Every poloxamer micelle consists of PEO shell and PPO core. After reaching CMC, the number of polymers existing in micelle is known as 'aggregation number' ${ }^{51}$. The sphere-shaped micelles generally show aggregation numbers ranging from few to more than hundred. PPO core has the ability to act like 'pool'. It offers hydrophobic drugs to incorporate inside the micelle(s). This process is termed as 'solubilization' ${ }^{, 52}$.

\section{Advantages of tri-block poloxamers over its PEO block}

For modification of hydrophobic surfaces, poloxamers show advantages over hydrophilic PEO. PPO being hydrophobic, a polymer composed of PO blocks alone is not used for the modification of hydrophobic polymeric surfaces. Poloxamers bind to the hydrophobic surface(s) in a more stable way by adapting their structure due to having both PEO and PPO chains. On the other hand, PEO alone binds with loose association and possesses high dynamicity. Surface-adhering patterns of PEO polymer and copolymer having PEO were investigated by Tan et $a .^{53}$. The protein adsorption to 
polystyrene (PS) colloids treated with PEO or poloxamer 338 (P338) was compared. If PEO chain is long, it resists proteins more than that having shorter chain. Thus, it was expected that after treating with PEO, improved or leastwise same effect can be observed like that of P338 in case of stable attachment for both of them. P338 coated PS has very low protein uptake ${ }^{54}$. On the other hand, protein uptake pattern by PEO treated and untreated compounds cannot be distinguished. It was concluded that it is easy for protein(s) to be adsorbed on the particles by dislocating homopolymer PEO. In case of P338 coating, dislocation by protein(s) is not so easy resulting in intact seam. For hydrophobic compounds, attraction is weak for homopolymer PEO and stronger for copolymer poloxamers.

\section{Benefits of poloxamers in drug formulation}

Different poloxamer excipients have been extensively used in pharmaceutical industries $^{55}$. They are used as emulsifier ${ }^{56}$, solubilizer for hydrophobic drugs ${ }^{57}$ and suspension stabilizer. They also find application in parenteral dosage forms ${ }^{58}$. Intravenous formulation of poloxamer $188(\mathrm{P} 188)$ is being marketed by the name RheothRx injection. It finds application in the clinical studies. An example of application is the thrombolysis in myocardial infarction. Poloxamers can serve different purposes: plasticizer, wetting agent, lubricant, etc. They have been using to formulate gel since they exhibit thermoreversible gelation in solid dosage forms, however this topic is not the object of the present review.

In a thorough review Moghimi et al. ${ }^{59}$ studied poloxamer application in nanoparticle engineering and medicine, such as long-circulating particles, macrophage 
stimulation, inhibition of multidrug resistance and adjuvant activities, as well as antithrombotic, haemorheological activities, cell membrane sealing, phagocyte activation and neutrophil degranulation.

As mentioned before, poloxamer helps drug loaded NPs/MPs to become stealth. In previous decades, some interesting studies have been published showing the higher existence period of poloxamer in the bloodstream with lower phagocytic uptake ${ }^{60,61,62,63}$. Poloxamer coated NPs/MPs are not recognized by macrophages and hence not engulfed by them. Macrophageal uptake study for P188 coated and uncoated PLGA NPs was made by RAW 264.7 cell lines ${ }^{64}$. Prussian blue staining detected existence of NPs inside cells. Uncoated NPs subjected to cell showed blue staining which was the indication of uptake by macrophages. On the other hand, same test didn't show any stain indicating nonbiorecognitive properties of P188 coated NPs. These results confirmed the potential to prolong NP circulation when administered in vivo. Further, uptake study using normal liver cells showed a dose dependent uptake of NPs functionalized by P188. Thus controlled adsorption may enlarge the binding of the stabilizer onto NPs.

Poloxamer coating is also useful for drug delivery to regional lymph nodes ${ }^{65,66}$. Therapeutic and diagnostic agents can be delivered to the regional lymph nodes using biodegradable poloxamer coated nanospheres following interstitial administration ${ }^{67}$. It was established that poloxamer coated PLGA NPs are suitable for diagnostic and therapeutic applications in clinical and experimental medicine ${ }^{67}$. NPs modified with poloxamers showed improved lymphatic uptake $(11 \%)$ compared to the control NPs (3 \%) in rat. Successful delivery to lymphatic system was also observed by Sanjula et al., who investigated lymphatic uptake of carvedilol-loaded NPs using male Wister rat ${ }^{68}$. 
Modified PS MPs with P407 were found to be efficient for bone marrow application in rabbit ${ }^{69}$. Approximately 50\% deposition of the injected MPs in the bone marrow of rabbits was measured. The uptake by marrow endothelial cells suggests that a specific interaction mechanism enables the penetration through the steric repulsive barrier of the cell surface ${ }^{69}$. In section 6.3 , delivery to brain, heart, liver, spleen, lungs and kidneys by poloxamer coated particles have also been discussed. Overall, it can be concluded that poloxamer coating can find widespread application for drug delivery in various parts of the body.

\section{Adsorption pattern and adlayer thickness of poloxamers}

Poloxamers readily dissolve in water. They are also soluble in many organic solvents. Based on the preparation method of hydrophobic NPs and MPs, they can be added in a different way and stage of preparation for the modification of hydrophobic surfaces.

By increasing the hydrophobicity of substrate surface, the binding between poloxamer and substrate is enhanced ${ }^{54}$. It is well known and can be easily understood that adsorption pattern is strongly dependent on the nature of the surface of a particle. Hydrophobic PPO has much stronger attraction for hydrophobic surface(s). Conversely, hydrophilic PEO has stronger attraction for water and extends towards aqueous phase. In general, the adsorption of poloxamer onto a hydrophobic polymeric nano- or microparticle surface is shown in Figure 2. When concentration is small, poloxamer molecules are adsorbed singly onto hydrophobic polymers. The result is monolayer formation on the substrate in which PEO blocks build "mushroom-type" conformation 8 
(Figure 2c) $)^{70}$. Nevertheless, efficient steric stabilization is observed for a denser adsorption layer of poloxamer (Figure 2a). It means when the surface concentration is comparatively high, extension of PEO blocks is stronger, which will eventuate "brushtype" conformation (Figure $2 \mathrm{~b}$ ) in accordance with Gennes et al. ${ }^{71}$. It is interesting to note that adlayer thickness is strongly affected by hydrophobicity and used poloxamer's HLB. P188 showed $20 \mathrm{~nm}$ adlayer onto PLGA NPs. At concentration close to or higher than CMC, thicker layer growth is observed because of hemimicelle adsorption ${ }^{72}$. The adlayer thickness depends on the method ${ }^{53}$. For coating PS with F108, field flow fractionation method gave higher adlayer thickness than photon correlation spectrophotometer (PCS) method.

Poloxamer adsorption on hydrophobic drug carriers increases the carrier's diameter and broadens the size distribution. The effect of surface characters on sterically stable PS MPs was investigated by mouse peritoneal macrophages ${ }^{73}$. Various poloxamers and poloxamine were applied to coat PS MPs, and the adlayer thickness varied between 3.5-15.8 nm depending on the conditions. For lower concentration of P338 $(0.01 \%)$, adsorption layer was almost $12 \mathrm{~nm}$ thick, while it was almost $16 \mathrm{~nm}$ at high concentration $(2 \%)^{73}$

A sharp plateau was found for adsorption isotherm of F68 onto PLGA NPs when the concentration was under the $\mathrm{CMC}^{72}$. This result was expected and agreed with the study performed by Kayes et al. $^{74}$ whose plateau adsorption value was close to $10 \times 10^{-4} \mathrm{~g} / \mathrm{m}^{2}$. For PS particles, Tadros et al. ${ }^{75}$ and Baker et al. ${ }^{76}$ found about $(8.5$ and $9.5) \times 10^{-4} \mathrm{~g} / \mathrm{m}^{2}$ plateau-adsorption value respectively, which coincide with the value obtained by Santander-Ortega $^{72}$, although just below the CMC the isotherm suffers from 9 
a little change. AFM studies revealed that homogeneous layers are not always formed by poloxamers. As mentioned before, under certain conditions nonionic surfactants show the tendency to construct micelles. That is why sometimes steep-isotherm can be obtained, nevertheless there is available theoretical explanation for them in the literature ${ }^{77,78}$. Isotherm curve alteration can be attributed to hemimicelle adsorption on PLGA particles $^{72}$. The calculated adlayer thickness was around $20 \mathrm{~nm}$ measured using PCS. For a PS latex having $56 \mathrm{~nm}$ diameter, Baker et al. ${ }^{76}$ obtained lower thickness which was only $6 \mathrm{~nm}$ using the identical polymer and optical measurement technique. The adsorption of poloxamer on hydrophobic surface is based on the hydrophobic attraction among PPO chain and the target surface. Lower hydrophobicity of PLGA related to PS might result in less compact adlayer onto PLGA surface by poloxamer.

The adsorption isotherms of PS NPs with P407 were measured for NPs of diameters 40 $\mathrm{nm}, 70 \mathrm{~nm}$ and $137 \mathrm{~nm}$ (Figure 3) ${ }^{79}$. They follow a Langmuirian-type profile initially showing steep slope, when equilibrium surfactant concentration is low, i.e. below 0.4 $\mathrm{mg} / \mathrm{ml}$. Above certain equilibrium concentration, an adsorption plateau is observed. The plateau values greatly agree with the results of another study ${ }^{80}$ using the same type of adsorption system(s). P407 plateau adsorption value on NPs can be seen from Table 2. $0.19,0.16$ and $0.18 \mu \mathrm{mol} / \mathrm{m}^{2}$ of $\mathrm{P} 407$ was adsorbed per surface unit for the $137 \mathrm{~nm}, 70$ $\mathrm{nm}$ and $40 \mathrm{~nm}$ particles, respectively (Figure 3). These results are in accordance with that obtained by Faers et al. ${ }^{81}$. Stolnik et al. ${ }^{79}$ also measured adlayer depth for every sampling point of isotherm. The hydrodynamic adlayer thickness for PS NPs of diameters $137 \mathrm{~nm}, 70 \mathrm{~nm}$ and $40 \mathrm{~nm}$ coated with poloxamer is also shown in Table $2^{79}$ (obtained using PCS).

10 
Table $3^{79}$ lists the values of chosen points on isotherm showing how P407 adsorbs on $40 \mathrm{~nm}$ PS NPs. It illustrates conformational changing of molecules onto NPs for the increase in quantity of P407 adsorbed. In case of adsorption of low amounts of P407 having less surface coverage, area counted for single PEO chain was larger. Adlayer thickness was also low indicating the absence of dense packing for P407 onto PS NPs. This less dense packing allows more space for lateral spreading of PEO. The surface is more crowded, when the amount of poloxamer adsorbed is higher, and the area occupied by single P407 decreases, although the adlayer becomes thicker. It is the indication of close packing of PEO chains. It also suggests perpendicular extension of PEO chains from NP surfaces.

In our most recent experiments (not published yet), we have investigated poloxamer adsorption onto PLGA NPs co-encapsulating model drug human serum albumin and magnetite. Double emulsion solvent evaporation method was used for NP preparation. Different concentrations of poloxamer F68 $(0.25,0.5$ and 1\% wt/vol) were used to coat the NPs which were redispersed in phosphate buffered saline (PBS) solution before the addition of poloxamer. The attachment of poloxamer onto PLGA surface was checked by size measurement carried out by Zetasizer Nano ZS (Malvern Instruments, UK). The volume mean size of our control sample was $199.8 \mathrm{~nm}$ and for coating with $0.5 \% \mathrm{~F} 68$, we got $56 \mathrm{~nm}$ enhancement in size which is comparable to the result obtained by Greenwood ${ }^{82}$. Figure 4 shows the size distribution of control and modified PLGA NPs obtained in our experiments. It was found that for 0.25 and $0.5 \%$ poloxamer concentrations, the size distribution of poloxamer covered PLGA NPs shifted towards higher particle size region with significant simultaneous increase in volume mean particle 
size. Santander-Ortega et al. $^{72}$ found a sharp increase in adsorption isotherm for F68 coating onto PLGA particles for low F68 concentration (up to $100 \mathrm{mg} / \mathrm{L}$ ) and above that concentration, the increase was quite steady and reached a plateau. In our study, we got sharp increase in size up to the concentration of $0.5 \%$. If number of poloxamer attached is higher, the surface will be highly crowded. Consequently, adlayer thickness increases ${ }^{80}$. Increase in poloxamer concentration from 0.5 to $1 \%$ resulted in both smaller and bigger particles than the control (Figure 4) indicating the formation of micelles, since the diameter of poloxamer micelle generally ranges from 10-200 nm as mentioned above.

From these studies it can be concluded that the method employed to find adlayer depth, the surfactant and the MP/NP characteristics significantly influence the adsorption pattern. Relationships of adlayer thickness with MP/NP size and with poloxamer units are discussed in section 7.

\section{Poloxamer coated hydrophobic carriers for drug delivery \\ 6.1. Surface modification by poloxamer to improve drug delivery}

Hydrophobic NPs loaded with drugs when administered intravenously face quick clearance from body system. They are cleaned by MPS and end up in spleen/liver. Thus, hydrophobicity of drug carriers limits their use in pharmaceutical fields. Short lifetime of hydrophobic drug carriers can be increased by modifying their surface, which will yield "stealth" particles and would not be detected by MPS ${ }^{10,83}$. Poloxamers are well applicable for this purpose.

The PPO blocks of poloxamers is capable of attaching the hydrophobic polymeric surfaces and the PEO blocks, which are extended outside the surface of hydrophobic polymeric surfaces, transforming the surface of drug loaded hydrophobic NPs hydrophilic to make NPs stealth. As a result, the MPS fails to recognize the NPs due to their hydrophilic nature. 
The fact can be lightened more explicitly with the Figures 5 and 6. PLGA NPs which are one of the most widely used hydrophobic drug carriers has been selected in the figures as an example. PLGA NPs form negatively charged surfaces in solution since they have carboxyl group in their structure (Figure 5a). These negatively charged drug loaded hydrophobic PLGA NPs adsorb plasma proteins after intravenous administration. For example, human serum albumin (HSA) will be adsorbed on PLGA NPs according to Figure 5b. Plasma protein adsorption enlarges the size of hydrophobic drug carrier particles. As a result, the particles will be visible to macrophages and will be removed quickly from the bloodstream. Poloxamer is adsorbed on the surface of a PLGA NP according to the mechanism shown in Figure 6a and protein adsorption is prevented by the mechanism shown in Figure 6b. As mentioned before poloxamer coating will make the particle "stealth" and macrophages will not be able to detect and engulf the particle.

Due to the quick detection of drug loaded particles by macrophages, they are engulfed by macrophages and removed quickly from the blood stream. Hence, they cannot reach the target site(s) or don't get sufficient time to release the drug, which will lead no effect of medication. Poloxamers, when adsorbed onto hydrophobic drug carriers, can depress quick clearance of those carriers from the blood stream. This is an essential point especially in case of targeted and sustained drug delivery. Adsorption of poloxamers onto the hydrophobic particles yields hydrophilic surface possessing reduced surface charge. The formation of such a surface not only limits the adsorption of opsonins resulting in extended circulation in the plasma, but also increases possible distribution to different organ sites. It can be mentioned here that opsonins are any blood serum component that aid in the process of phagocytic recognition. Opsonization is the process by which foreign particle(s) or organism(s) becomes covered with opsonin proteins, thereby making it more visible to phagocytic cells ${ }^{84}$. Phagocytosis can occur after 
opsonization. Phagocytosis is the engulfing and eventual destruction or removal of foreign materials from the bloodstream. For non-biodegradable polymeric NPs, accumulation of particles in organs (most commonly the liver and spleen) can lead to toxicity and other negative side effects ${ }^{83,85,86}$.

\subsection{Poloxamer to depress quick clearance from the blood stream}

Illum and Davis ${ }^{87}$ coated the surface of hydrophobic PS with poloxamer.

If the PS was coated with P188, significantly higher amount of particles can get to the lung. P338 coated particles show high-level in lungs, carcass and spleen. The effect of the used P188 and P338 with different $\mathrm{M}_{\mathrm{w}}$ and characteristics was investigated. Hydrophilic NPs/MPs having high $\mathrm{M}_{\mathrm{w}}$ P338 coating showed appropriate colloidal stability with very low adhesive-properties ${ }^{88}$. Hence, high $\mathrm{M}_{\mathrm{w}}$ poloxamer (P338) has better effectivity when compared to those with lower $\mathrm{M}_{\mathrm{w}}$.

Illum et al. ${ }^{86}$ studied phagocytic uptake of PS coated with poloxamers. In general it was found that the higher the adlayer thickness, the lower the relative phagocytic uptake as shown in Figure $7^{74}$.

These results are in agreement with the predictions of the various theories that explain the phenomenon of steric stabilization which can also be applied to the interaction of particles with phagocytic cells. It can be observed if the regression line (Figure 7) is extrapolated to zero, an adlayer of $23 \mathrm{~nm}$ thick will be needed to get over van der Waals attractive forces between macrophages and 5.25 $\mu \mathrm{m}$ MPs. Prediction of adlayer thickness, needed to achieve equal stabilizing effect for little NPs (e.g. 60nm), is not very easy. Van der Waals attractive force has direct relation to particles radii (a). 
According to the equation (1) it is expected that a $10 \mathrm{~nm}$ thick adsorbed layer will be enough for providing both steric stabilization of $60 \mathrm{~nm}$ PS particles in terms of their aggregative propensity and a lack of interaction with macrophages ${ }^{86}$ :

$$
V A \approx \frac{a A_{\text {eff }}}{12 h}----------(1)
$$

where, $\mathrm{VA}=$ van der Waals attractive forces.

$\mathrm{a}=$ particles radii.

$\mathrm{A}_{\text {eff }}=$ composite Hamaker constant.

$\mathrm{h}=$ Planck's constant.

Phagocytosis of PS latex particles coated with 22 different poloxamers was studied by Rudt et al. ${ }^{89}$. A tendency was found for reduction of phagocytic uptake for poloxamers coated particles if $\mathrm{M}_{\mathrm{w}}$ is more than 4000. This is obviously a generalization, although few exceptions were observed, notably poloxamer 108 and 333. They had the same $\mathrm{M}_{\mathrm{w}}$ but different relative phagocytic uptakes (94.5\% and 3.3\%, respectively). When considering poloxamers with the same PPO chain length, variations in hydrophilic PEO chain length did not seem to show significant effect on phagocytic uptake. As an example, relative phagocytic uptakes of poloxamers 331,333,334,335, and 338 were 22.9, 3.3, 2.5, 7.2 and $6.0 \%$, respectively. However, great effect is observed for PPO chain length variation. If more than 39 units are present in PPO chains, better protection against phagocytosis is observed, which might be because of more secure adsorption onto particle surfaces. The secure adsorption is capable of preventing displacement of the adsorbed poloxamer very well by other species, thus limiting the phagocytosis of drug carriers. Another reason which imparts a little part in this mechanism is steric 
stabilisation effects. However, too short PEO chains cannot provide sufficient hydrophilicity to the surface of the drug carrier to prevent opsonisation, and there exists possibility of steric stabilization as well. Finally, it was concluded that a PPO block of about 40 units will be the minimum length for achieving great decrease or preventing phagocytosis (Figure 8). This type of minimum length can be required for strong anchoring of poloxamers onto drug carrier surface which will provide enough thickness and hydrophilicity.

Thus, a conclusion can be drawn: poloxamers adsorption onto hydrophobic polymeric drug carrier surfaces produces hydrophilic surfaces reducing surface-charge. These sufficiently hydrophilic particles can prevent opsonisation, which in turns increase the life time of carrier particles in blood circulation as well as giving the possibility of distribution to different organ sites.

\subsection{Drug delivery and release profile from poloxamer coated drug carriers}

Poloxamer coating is capable to generate higher residence time in the plasma than uncoated NPs ${ }^{90,91,92}$. Fluorescently labelled PLGA particles coated with PEG and Pluronic F127 had higher plasma concentration than the uncoated ones while used in oral formulations $^{90}$. PLGA carriers without poloxamer coating were detected in the brain, heart, liver, spleen, lungs and kidneys over a period of 7 days. Interestingly, not even a single particle was detected in the plasma in the lack of surface functionalization. The biodistribution profile for 1\% F127 and PEG coated particles administered orally is shown in Figure 9. Though NPs were accumulated in spleen and brain, the NPs in these tissues at high doses were established to be safe ${ }^{91}$. 
Loperamide, an opioid drug cannot cross the blood brain barrier (BBB) although effective as antinociceptive if injected directly to the brain. P188-coated PLGA-PEGPLGA (PEP) triblock copolymer NPs containing the drug showed 14.4 to $21.2 \%$ penetration $^{93}$, which was much higher than either with PLGA NPs (4.3\%) or with PEP NPs $(8.2 \%)$. The in vitro BBB permeation percentage of PEP obtained was 13.7 folds higher than just the loperamide solution. It shows that PEP is capable of encapsulating and transporting drugs across BBB which is normally impossible. Moreover, P188 coated PEP resulted in improved cellular uptake in BBB model compared to PEP coated with polysorbate80 (Ps80). Biopsy studies also confirmed increased penetration for P188 coated PEP over non-coated one. In brain tissue(s), NPs deposition for PEP coating with P188 showed significantly higher concentration than both PEP and PLGA NPs. Maximal possible antinociception effect (MPE) for the P188-coated PEP was 21 to $35 \%$ after 2 and half hours of intravenous loperamide administration whereas that of just the PEP was $11.6 \%$.

Various proteins quickly attach onto foreign NPs after being exposed to serum or plasma $^{94,95}$. The type and the relative amount of adsorbed proteins can decide the fate of particles. In 1989, this concept was originally defined as "differential protein adsorption" ${ }^{\prime 95}$. Based on this concept, the hypothesis was postulated that an adsorption of the ApoE or ApoB (apolipoprotein E or B) on Ps80-coated NPs could be responsible for the interaction with the BBB and the subsequent endocytosis ${ }^{95,96,97}$. ApoE attaches the particles to the ApoE receptor of the endothelial cells of the $\mathrm{BBB}^{98}$. As a result, the particles are taken up by endocytosis into the cells. In the cells, the drug is released from the particle and diffuses into the surrounding brain tissue. Schematically the brain uptake 
of surfactant coated NPs can be illustrated as shown in Figure 10, which is based on endocytosis.

Hydrophobic polybutyl cyanoacrylate (PBCA) is an effective drug carrier. PBCA and PLGA NPs having P188 coating loaded with doxorubicin (Dox) appears to be interesting and hopeful for treating brain tumors. These NPs yield $40 \%$ of long-term survivors. P188 was an effective coating agent for both PLGA and PBCA NPs. However, coating with Ps80 showed effectiveness only for PBCA and not for PLGA NPs ${ }^{99}$. Ps80and P188-coated PBCA loaded with Dox NPs for anti-tumor effect resulted in 35\% and $20 \%$ of long-term survivors.

Recently, seven different formulations including Dox was evaluated according to their anti-tumor efficacy ${ }^{100}$. All formulations increased the survival time in brain tumorcontaining specimens by comparing with control one that is shown in Figure 11. Poloxamer (P188) containing formulations represented the highest effectiveness. Longterm remission (more than 100 days without tumor) in $40 \%$ of the specimens could be achieved. Dox-PLGA having P188/Ps80 resulted in more than $20 \%$ of long-term survivors $^{101,102,103}$. Nevertheless, the efficacy of uncoated NPs (without poloxamer and polysorbate) was almost the same like Dox-solution. For uncoated NPs, just a single specimen survived after day 30. Free Dox concentration in the brain remained below the detection limit of $0.1 \mu \mathrm{g} / \mathrm{ml}$. Dox concentration delivered to the brain by Ps 80 coated PBCA NPs was found to be comparatively very high (6 $\mu \mathrm{g} / \mathrm{g}$ tissue), showing significantly improved Dox-delivery to the brain because of used coating material ${ }^{104}$. Stabilizers yielded NPs of similar size ${ }^{103}$, although dextran-stabilized PBCA NPs had higher polydispersity and less negative surface charge enabling higher loading of Dox. 
On the other hand, drug-loaded P188-stabilized NPs showed lower drug loading (45\% for P188 and $65 \%$ for dextran) than that of dextran-stabilized particles.

Cytotoxicity of Dox loaded PBCA NPs, coated with Ps80, P188 or poloxamine 908 pharmaceutical surfactants was investigated in rat glioma cell lines ${ }^{105}$. Drug accumulation determined by confocal scanning microscopy revealed higher accumulation of nanoparticle-bound Dox after coating the particle surface with Ps80, which corroborated the results of the previous studies. Nanoparticle-associated Dox showed a higher cytotoxicity than the free drug in both tests, when the Ps80 was used to coat the NPs. On the other hand, P188 and poloxamine 908 showed negligible influences. This phenomenon can be attributed to more efficient transport of the Ps80-coated NPs into the cells.

Poloxamer is able to totally inhibit protein adsorption onto the PLGA 37.5/25 layer $^{106}$. When P188 was present in the formulation, it exhibited a continuous release of lysozyme over 3 weeks without any burst effect (Figure 12). After 3 weeks, a plateau was reached due to additional destabilising mechanisms concomitant with polymer degradation. To promote the release of lysozyme in the latter stage of release, a PEP triblock copolymer was used, which resulted in continuous lysozyme release over 45 days in a biologically active form with limited initial burst (9\%). Considering the wettability of the polymer, after 45 days the poloxamer and the PEG segments are leached thereby limiting their protective function, and according to the adaptation of hydration kinetics, the microspheres might provide optimal protein release.

As a summary, the investigations undoubtedly indicate the protein adsorption hindrance and thus, possibility of achieving prolonged residence time in the bloodstream 
using poloxamer surfactants even via oral administration. Detection of the comparatively high amount of NPs in kidney, lungs and liver might be because of nonhomogeneous attachment of coating agents onto NPs. Poloxamers have the ability to (i) be incorporated into membranes and to change microviscosity (ii) decrease ATP (Adenosine triphosphate) levels (iii) resist drug efflux transporters, which might result in enhanced penetration and drug transport through the BBB. These features help the efficient use of microencapsulated active agents functionalized with poloxamers in controlled drug delivery systems. It is noted that results suggest that for NP formulations in vitro observations cannot easily correlate or represent the in vivo behavior of the NPs.

\section{Correlation of particle size, poloxamer units, adlayer thickness and drug release 7.1. Effect of particle size on adlayer thickness}

A small particle adsorbs less polymeric molecules per unit area in comparison to a large one resulting in lower thickness than larger particles as shown in Figure $13^{55}$. This can be also explained by the following equation showing how the surface area filled by unit poloxamer molecule depends on the particle diameter ${ }^{54}$ :

$$
\frac{\text { Surface area }}{\text { Molecule }}=\frac{\pi d_{A}^{2} M W}{N_{A} m_{B}}
$$

where $\mathrm{d}_{\mathrm{A}}=$ diameter of core NP or MP

MW = molecular weight of adsorbed poloxamer

$\mathrm{m}_{\mathrm{B}}=$ mass of adsorbed poloxamer

$\mathrm{N}_{\mathrm{A}}=$ Avogadro's number.

From the equation it can be seen that the surface area covered by poloxamer is directly proportional to the square of the diameter of core NP or MP $\left(\mathrm{d}_{\mathrm{A}}\right)$.

The thickness of the adsorbed poloxamers to PS MPs was studied using field flow fractionation technique, and it was found that the thickness increases with particle size ${ }^{54}$. 20 
The thickness increased from $60 \mathrm{~nm}$ to $270 \mathrm{~nm}$ applying F108, F88, F68 coating but not for $\mathrm{P}^{105^{77}}$. As a contrary, Baker and $\mathrm{Berg}^{76}$ and Killmann et al. ${ }^{107}$ measured adlayer thickness of poloxamer on PS particles using PCS. They found that the adsorption does not depend on the particle size, and the adlayer thickness decreases with increasing NPs/MPs radii. For adsorption of F108 on PS, Bevan et al. ${ }^{108}$ has quoted $12 \mathrm{~nm}$ and 15 $\mathrm{nm}$ thick adlayer onto $140 \mathrm{~nm}$ and $400 \mathrm{~nm}$ NPs, respectively. Greenwood et al. ${ }^{82}$ found strong size dependence of adlayer thickness for P407 onto PS NPs. The adlayer showed a tendency to increase from $11 \mathrm{~nm}$ to $37 \mathrm{~nm}$ onto NPs of size $40 \mathrm{~nm}$ and $217 \mathrm{~nm}$, respectively. $\mathrm{Li}$ et al. ${ }^{54}$ observed strong dependence of surface concentration and adsorbed layer thickness on substrate size. On little PS-latex (69 nm), poloxamer adsorption layer was almost double thick of radius of gyration $(\mathrm{Rg})$ of its PEO blocks. On the other hand, for bigger size (272 nm PS), PEO blocks showed large extension and adlayer was about 4Rg thick. On small particles, the surface-density of adsorbed polymeric molecules is little. The consequence is highly mobile adsorbed polymer chains. Conversely, on large particles, the adlayer is mobile to a lesser extent due to more crowded surface. An adsorbed polymeric chain moves more freely if surface packing is less (little NPs/MPs) in comparison to highly dense packing (big NPs/MPs).

\subsection{Effect of units of the poloxamers on adlayer thickness}

Adlayer thickness strongly depends on EO units and not influenced by PO number $^{73}$. Figure 14 depicts the direct dependence of adlayer depth on EO and PO content. This is the indication that the PO adsorption occurs on substrate surface whereas looping or tailing is observed due to the extension of EO to aqueous phase. This can be 
more clearly understood from the Table 4 obtained by Illum et al. ${ }^{73}$ who studied adsorption of poloxamer on polystyrene particles. P338 having 128 EO units gives 15.8 nm adlayer thickness whereas P188 having 75 EO units gives less thick adlayer $(7.6 \mathrm{~nm})$. This result is in agreement with the one found by Kayes et al. ${ }^{74}$. Faers ${ }^{81}$ observed increase in adlayer thickness for enhancement of $\mathrm{M}_{\mathrm{w}}$ of PEO chain.

\subsection{Effects of the adlayer thickness on release profile}

The release pattern depends on many factors e.g. matrix structure, type of drug loaded, size of drug molecules, distribution of drug molecules inside the matrix, etc. It is known that drug loading and drug particle size distribution determine the geometry and the topology of pores and channels which determine drug diffusion from the hydrophobic matrix $^{109}$. It is not an easy task to make a correlation between the coating thickness and the release profile for drug loaded NPs and MPs. Only the coated layer covering the surface i.e. PPO block affects the release profile. Nano- and microparticle surfaces are porous and may also contain cracks which originate from fabrication process. Drugs escape from the polymeric matrices through the cracks and pores. Poloxamer, used for coating, may cover many of the pores (not all of them). After surface covering, the coated portion will prevent diffusion of drug and initial burst release.

The prevention of the drug diffusion has direct effect on the drug release. If the diffusion is low, the drug release time will be extended. On the other hand, PEO blocks extends to the outer aqueous phase and make the particles stealth to macrophages. It can be assumed that they do not have direct effect on the release profile. However, if the extended chain length of PEO is not sufficiently thick, they won't be able to prevent protein adsorption on the particle surface as shown in Figure 6b. It is well known that the drug release rates decrease with increasing coating thickness due to enhanced length of diffusion pathways for tablet coating, which cannot be applied directly for poloxamer coating, nevertheless, it can provide an approximation for estimating the poloxamer effect. In addition, the surface coating will decrease the initial burst release ${ }^{110}$. 
Diffusion-controlled drug release from matrix-type drug-delivery systems can be expressed by the popular equation given by Higuchi ${ }^{111}$,

$$
M_{t}=A \sqrt{\frac{D_{i} \varepsilon C_{s}\left(2 C_{d}-\varepsilon C_{s}\right) t}{\tau}}
$$

where $M_{t}$ is the drug amount released at time $t, A$ is the surface area of the matrix, $D_{i}$ is the diffusivity of the drug, $\varepsilon$ is the porosity of the matrix, $\tau$ is tortuosity of the matrix, $\mathrm{C}_{\mathrm{s}}$ is the solubility, $C_{d}$ is the concentration of the drug.

Poloxamer attachment increases the size of NPs and MPs. Consequently, surface area A will decrease, and smaller value of $\mathrm{M}_{\mathrm{t}}$, i.e. lower drug release will be obtained.

\section{Conclusion}

Poloxamers are triblock copolymers having amphiphilic character and have the ability to interact with hydrophobic drug carrier surfaces and biological membranes. Drug carriers are confronted with difficulties during the route to the target organ that need to overcome before they reach its target site(s) within the body. The most important barrier is the adsorption of plasma proteins which make them more visible to phagocytic cells, then, they are immediately engulfed by macrophages and removed quickly from the blood stream. Poloxamer coating makes hydrophobic carriers "stealth", hence they can reach the target site(s), where they can perform their biological roles. Poloxamers are adsorbed onto hydrophobic carriers by their PPO block, whereas PEO block is extended toward the aqueous dispersant and make the surface of the carrier hydrophilic. The adsorption pattern and the adlayer thickness are strongly affected by the nature of the surface of carrier particles. The concentration of poloxamer is also vital since the adlayer thickness and thus the final size of drug carriers generally show the tendency to grow with the increase in poloxamer concentration. The particle size also influences the adlayer thickness, since the smaller particles take up fewer poloxamer molecules per unit 
area than the larger ones, and in turn show lower thickness than the adlayer found on bigger particles. Poloxamer coated stealth carriers possess increased life time in the blood stream and show decreased phagocytic uptake. Most widely investigated biodegradable polymers for drug delivery, PLGAs show excellent life time in the blood stream after being coated by poloxamers. In vitro and in vivo studies certified that improved drug delivery and better release profile can be obtained from poloxamer coated drug carriers. It is expected that in the future more in vivo studies will be conducted, and more clinical trials will be performed to utilize promising coating agent poloxamer in the field of drug delivery.

Acknowledgement: Marie Curie Initial Training Network (Agreement: 264722).

\author{
Abbreviations \\ Apo $=$ apolipoprotein \\ $\mathrm{BBB}=$ blood brain barrier \\ $\mathrm{CMC}=$ critical micelle concentration \\ Dox $=$ doxorubicin \\ $\mathrm{EPR}=$ enhanced permeability and retention \\ HLB $=$ hydrophilic-lipophilic balance \\ $\mathrm{M}_{\mathrm{w}}=$ molecular weight \\ MPS = mononuclear phagocytic system \\ MPs $=$ microparticles \\ NPs $=$ nanoparticles
}




$$
\begin{aligned}
& \text { PBCA = poly(butyl cyanoacrylate }) \\
& \text { PEG = poly(ethylene glycol }) \\
& \text { PLGA = poly(lactide-co-glycolide }) \\
& \text { PLGA-PEG-PLGA = PEP } \\
& \text { P188 = poloxamer } 188 \\
& \text { P338 = poloxamer } 338 \\
& \text { P407 = poloxamer } 407 \\
& \text { F88 = Poloxamer } 238 \\
& \text { PS = polystyrene } \\
& \text { Ps } 80=\text { polysorbate } 80
\end{aligned}
$$

\section{References}

1. Stanislawski, L.; De Nechaud, B.; Christel, P. "Plasma protein adsorption to artificial ligament fibers", J. Biomed. Mater. Res. 1995, 29, 315-323.

2. Tamilvanan, S.; Schmidt, S.; Muller, R. H.; Benita, S. "In vitro adsorption of plasma proteins onto the surface (charges) modified-submicron emulsions for intravenous administration", Eur. J. Pharm. Biopharm. 2005, 59, 1-7.

3. Chang, Y.; Chu, W. L.; Chen, W. Y.; Zheng, J.; Liu, L.; Ruaan, R. C.;Higuchi, A. "A systematic SPR study of human plasma protein adsorption behavior on the controlled surface packing of self-assembled poly(ethylene oxide) triblock copolymer surfaces", $J$. Biomed. Mater. Res., Part A 2010, 93, 400-408.

4. Nelson, P. J.; Rees, A. J.; Griffin, M. D.; Hughes, J.; Kurts, C.; Duffield, J. "The renal mononuclear phagocytic system", J. Am. Soc. Nephrol. 2012, 23, 194-203. 
5. Prabhakar, U.; Maeda, H.; Jain, R. K.; Sevick-Muraca, E. M.; Zamboni, W.; Farokhzad, O. C.; Barry, S. T.; Gabizon, A.; Grodzinski, P.; Blakey, D. C. "Challenges and Key Considerations of the Enhanced Permeability and Retention Effect for Nanomedicine Drug Delivery in Oncology", Cancer Res. 2013, 73, 2412-2417.

6. Attarwala, H.; Amiji, M. "Multi-compartmental nanoparticles-in-emulsion formulation for macrophage-specific anti-inflammatory gene delivery", Pharm. Res. 2012, 29, 16371649.

7. Peer, D. "Immunotoxicity derived from manipulating leukocytes with lipid-based nanoparticles", Adv. Drug Delivery Rev. 2012, 64, 1738-1748.

8. Landesman-Milo, D.; Peer, D. "Altering the immune response with lipid-based nanoparticles", J. Control. Release 2012, 161, 600-608.

9. Peer, D. "A daunting task: manipulating leukocyte function with RNAi", Immunol. Rev. 2013, 253, 185-197.

10. Gref, R.; Luck, M.; Quellec, P.; Marchand, M.; Dellacherie, E.; Harnisch, S.; Blunk, T.; Muller, R. H. "'Stealth' corona-core nanoparticles surface modified by polyethylene glycol (PEG): influences of the corona (PEG chain length and surface density) and of the core composition on phagocytic uptake and plasma protein adsorption", Colloid Surface B 2000, 18, 301-313.

11. Walker, G. M.; Bell, S. E. J.; Greene, K.; Jones, D. S.; Andrews, G. P. "Characterisation of fluidised bed granulation processes using in-situ Raman spectroscopy", Chem. Eng. Sci. 2009, 64, 91-98. 
12. Zou, W.; Liu, C.; Chen, Z.; Zhang, N. "Studies on bioadhesive PLGA nanoparticles: A promising gene delivery system for efficient gene therapy to lung cancer", Int. J. Pharm. 2009, 370, 187-195.

13. Bonacucina, G.; Spina, M.; Misici-Falzi, M.; Cespi, M.; Pucciarelli, S.; Angeletti, M.; Palmieri, G. F. "Effect of hydroxypropyl beta-cyclodextrin on the self-assembling and thermogelation properties of Poloxamer 407", Eur. J. Pharm. Sci. 2007, 32, 115-122.

14. Walker, G.; Bell, S. E. J.; Vann, M.; Jones, D. S.; Andrews, G. "Fluidised bed characterisation using Raman spectroscopy: Applications to pharmaceutical processing", Chem. Eng. Sci. 2007, 62, 3832-3838.

15. Brigante, M.; Schulz, P. "Aggregation and Adsorption at the Air-Solution Interface of the Cetyltrimethyl Ammonium Tosylate With Two Poly(oxyethylene)Poly(oxypropylene)-Poly(oxyethylene) Block Copolymers Aqueous Mixtures", J. Surfactants Deterg. 2011, 14, 439-453.

16. Mustafi, D.; Smith, C. M.; Makinen, M. W.; Lee, R. C. "Multi-block poloxamer surfactants suppress aggregation of denatured proteins", Biochim. Biophys. Acta. 2008, 1780, 7-15.

17. Santander-Ortega, M. J.; Csaba, N.; Alonso, M. J.; Ortega-Vinuesa, J. L.; BastosGonzález, D. "Stability and physicochemical characteristics of PLGA, PLGA:poloxamer and PLGA:poloxamine blend nanoparticles: A comparative study", Colloid Surface A 2007, 296, 132-140.

18. Dumortier, G.; Grossiord, J. L.; Agnely, F.; Chaumeil, J. C. "A review of poloxamer 407 pharmaceutical and pharmacological characteristics", Pharm. Res. 2006, 23, 27092728. 
19. Escobar-Chavez, J. J.; Lopez-Cervantes, M.; Naik, A.; Kalia, Y. N.; QuintanarGuerrero, D.; Ganem-Quintanar, A. "Applications of thermo-reversible pluronic F-127 gels in pharmaceutical formulations", J. Pharm. Pharm. Sci. 2006, 9, 339-358.

20. Kabanov, A. V.; Batrakova, E. V.; Alakhov, V. Y. "Pluronic block copolymers as novel polymer therapeutics for drug and gene delivery", J. Control. Release 2002, 82, 189-212.

21. Batrakova, E. V.; Kabanov, A. V. "Pluronic block copolymers: evolution of drug delivery concept from inert nanocarriers to biological response modifiers", J. Control. Release 2008, 130, 98-106.

22. Schmolka, I. R. "A Review of Block Polymer Surfactants", J. Am. Oil Chem. Soc. $1977,54,110-116$.

23. Li, Y.; Chen, P. S.; Huang, S. D. "Water with low concentration of surfactant in dispersed solvent-assisted emulsion dispersive liquid-liquid microextraction for the determination of organochlorine pesticides in aqueous samples", J. Chromatogr. A 2013.

24. Paschalis Alexandridis, T. A. H. "Poly (ethylene oxide)-poly (propylene oxide)-poly (ethylene oxide) block copolymer surfactants in aqueous solutions and at interfaces: thermodynamics, structure, dynamics, and modeling", Colloid Surface A 1995, 96, 1-46.

25. Al-Saden, A. A.; T. L. W., A.T Florence. "Poloxamer association in aqueous solution", J. Colloid Interf. Sci. 1982, 90, 303-309.

26. Hofig, I.;Atkinson, M. J.;Mall, S.;Krackhardt, A. M.;Thirion, C.;Anastasov, N. "Poloxamer synperonic F108 improves cellular transduction with lentiviral vectors", $J$. Gene Med. 2012, 14, 549-560. 
27. Niu, G.; Du, F.; Song, L.; Zhang, H.; Yang, J.; Cao, H.; Zheng, Y.; Yang, Z.; Wang, G.; Yang, H.; Zhu, S. "Synthesis and characterization of reactive poloxamer 407s for biomedical applications", J. Control. Release 2009, 138, 49-56.

28. Lin, H.-R.; Tseng, C.-C.; Lin, Y.-J.; Ling, M.-H. "A Novel In-Situ-Gelling Liquid Suppository for Site-Targeting Delivery of Anti-Colorectal Cancer Drugs", J. Biomat. Sci-Polym. E. 2012, 23, 807-822.

29. Malmsten, M.; Lindman, B. "Self-assembly in aqueous block copolymer solutions", Macromolecules 1992, 25, 5440-5445.

30. Zukang Zhou, B. C. "Light-scattering study on the association behavior of triblock polymers of ethylene oxide and propylene oxide in aqueous solution", J. Colloid Interf. Sci. 1988, 126, 171-180.

31. Causse, J.; Oberdisse, J.; Jestin, J.; Lagerge, S. "Small-Angle Neutron Scattering Study of Solubilization of Tributyl Phosphate in Aqueous Solutions of L64 Pluronic Triblock Copolymers", Langmuir 2010, 26, 15745-15753.

32. Wanka, G.;Hoffmann, H.;Ulbricht, W. "The aggregation behavior of poly(oxyethylene)-poly-(oxypropylene)-poly-(oxyethylene)-block-copolymers in aqueous solution", Colloid Polym. Sci. 1990, 268, 101-117.

33. Mortensen, K.; Pedersen, J. S. "Structural study on the micelle formation of poly(ethylene oxide)-poly(propylene oxide)-poly(ethylene oxide) triblock copolymer in aqueous solution", Macromolecules 1993, 26, 805-812.

34. Nogueiras-Nieto, L.; Sobarzo-Sanchez, E.; Gomez-Amoza, J. L.; Otero-Espinar, F. J. "Competitive displacement of drugs from cyclodextrin inclusion complex by 
polypseudorotaxane formation with poloxamer: implications in drug solubilization and delivery", Eur. J. Pharm. Biopharm. 2012, 80, 585-595.

35. Nogueiras-Nieto, L.; Begona Delgado-Charro, M.; Otero-Espinar, F. J. "Thermogelling hydrogels of cyclodextrin/poloxamer polypseudorotaxanes as aqueousbased nail lacquers: application to the delivery of triamcinolone acetonide and ciclopirox olamine", Eur. J. Pharm. Biopharm. 2013, 83, 370-377.

36. Yuan, Y.; Cui, Y.; Zhang, L.; Zhu, H. P.; Guo, Y. S.; Zhong, B.; Hu, X.; Zhang, L.; Wang, X. H.; Chen, L. "Thermosensitive and mucoadhesive in situ gel based on poloxamer as new carrier for rectal administration of nimesulide", Int. J. Pharm. 2012, 430, 114-119.

37. Hurter, P. N.; Scheutjens, J. M. H. M.; Hatton, T. A. "Molecular modeling of micelle formation and solubilization in block copolymer micelles. 1. A self-consistent mean-field lattice theory", Macromolecules 1993, 26, 5592-5601.

38. Nagarajan, R. "Solubilization of hydrocarbons and resulting aggregate shape

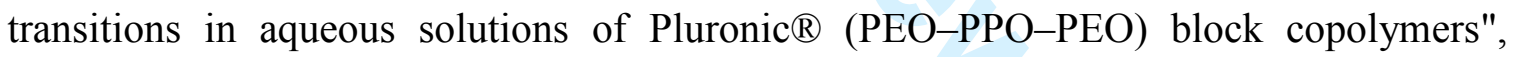
Colloid Surface B 1999, 16, 55-72.

39. Hurter, P. N.; Scheutjens, J. M. H. M.; Hatton, T. A. "Molecular modeling of micelle formation and solubilization in block copolymer micelles. 2. Lattice theory for monomers with internal degrees of freedom", Macromolecules 1993, 26, 5030-5040.

40. Alexandridis, P.; Holzwarth, J. F.; Hatton, T. A. "Micellization of Poly(ethylene oxide)-Poly(propylene oxide)-Poly(ethylene oxide) Triblock Copolymers in Aqueous Solutions: Thermodynamics of Copolymer Association", Macromolecules 1994, 27, 2414-2425. 
41. Alexandridis, P.; Athanassiou, V.; Fukuda, S.; Hatton, T. A. "Surface Activity of Poly(ethylene oxide)-block-Poly(propylene oxide)-block-Poly(ethylene oxide) Copolymers", Langmuir 1994, 10, 2604-2612.

42. Kochurova, N. N.; Airapetova, E. R.; Abdulin, N. G.; Korotkikh, O. P.; Lezov, A. V.; Petzold, G. "Viscosity of aqueous micellar solutions of surfactants", Colloid J. 2012, 74, 564-568.

43. Eustathopoulos, N.; Drevet, B. "Surface tension of liquid silicon: High or low value?", J. Cryst. Growth 2013, 371, 77-83.

44. Jiang, Z.; Reilly, J. "Chromatography approaches for early screening of the phospholipidosis-inducing potential of pharmaceuticals", J. Pharmaceut. Biomed. 2012, 61, 184-190.

45. Sastry, N. V.; Punjabi, S. H.; Aswal, V. K.; Goyal, P. S. "Small Angle Neutron Scattering and Viscosity Measurements on Silicone, Ionic, and Nonionic Surfactant Mixed Systems in Aqueous Solutions", J. Dispers. Sci. Technolo. 2011, 33, 245-253.

46. Sanada, Y.; Akiba, I.; Sakurai, K.; Shiraishi, K.; Yokoyama, M.; Mylonas, E.; Ohta, N.; Yagi, N.; Shinohara, Y.; Amemiya, Y. "Hydrophobic Molecules Infiltrating into the Poly(ethylene glycol) Domain of the Core/Shell Interface of a Polymeric Micelle: Evidence Obtained with Anomalous Small-Angle X-ray Scattering", J. Am. Chem. Soc. $2013,135,2574-2582$.

47. Paillet, S.; Grassl, B.; Desbrieres, J. "Rapid and quantitative determination of critical micelle concentration by automatic continuous mixing and static light scattering", Anal. Chim. Acta 2009, 636, 236-241. 
48. Thompson, A. L.; Love, B. J. "Thermodynamic properties of aqueous PEO-PPO-PEO micelles with added methylparaben determined by differential scanning calorimetry", $J$. Colloid Interf. Sci. 2013, 398, 270-272.

49. Savaroglu, G.; Genc, L. "Determination of micelle formation of ketorolac tromethamine in aqueous media by acoustic measurements", Thermochim. Acta 2013, $552,5-9$.

50. Li, N.; Wang, J.; Yang, X.; Li, L. "Novel nanogels as drug delivery systems for poorly soluble anticancer drugs", Colloid Surface B 2011, 83, 237-244.

51. Chandrasekharan, P.; Maity, D.; Yong, C. X.; Chuang, K. H.; Ding, J.; Feng, S. S. "Vitamin E (D-alpha-tocopheryl-co-poly(ethylene glycol) 1000 succinate) micellessuperparamagnetic iron oxide nanoparticles for enhanced thermotherapy and MRI", Biomaterials 2011, 32, 5663-5672.

52. Parmar, A.; Parekh, P.; Bahadur, P. "Solubilization and Release of a Model Drug Nimesulide from PEO-PPO-PEO Block Copolymer Core-Shell Micelles: Effect of Size of PEO Blocks", J. Solution. Chem. 2013, 42, 80-101.

53. Tan, J. S.; Butterfield, D. E.; Voycheck, C. L.; Caldwell, K. D.; Li, J. T. "Surface modification of nanoparticles by $\mathrm{PEO} / \mathrm{PPO}$ block copolymers to minimize interactions with blood components and prolong blood circulation in rats", Biomaterials 1993, 14, $823-833$.

54. Li, J.-T.; Caldwell, K. D.; Rapoport, N. "Surface Properties of Pluronic-Coated Polymeric Colloids", Langmuir 1994, 10, 4475-4482. 
55. Younis, H. S.; Shawer, M.; Palacio, K.; Gukasyan, H. J.; Stevens, G. J.; Evering, W. "An assessment of the ocular safety of inactive excipients following sub-tenon injection in rabbits", J. Ocul. Pharmacol. Th. 2008, 24, 206-216.

56. Feczkó, T.; Tóth, J.; Gyenis, J. "Comparison of the preparation of PLGA-BSA nanoand microparticles by PVA, poloxamer and PVP", Colloid Surface A 2008, 319, 188-195. 57. Shah, T. J.; Amin, A. F.; Parikh, J. R.; Parikh, R. H. "Process optimization and characterization of poloxamer solid dispersions of a poorly water-soluble drug", $A A P S$ PharmSciTech 2007, 8, E18-E24.

58. Wulff-Pérez, M.; Torcello-Gómez, A.; Martín-Rodríguez, A.; Gálvez-Ruiz, M. J.; de Vicente, J. "Bulk and interfacial viscoelasticity in concentrated emulsions: The role of the surfactant", Food Hydrocolloid 2011, 25, 677-686.

59. Moghimi, S. M.; Hunter, A. C. "Poloxamers and poloxamines in nanoparticle engineering and experimental medicine", Trends Biotechnol. 2000, 18, 412-420.

60. Leu, D.; Manthey, B.; Kreuter, J.; Speiser, P.; Deluca, P. P. "Distribution and elimination of coated polymethyl [2-14C]methacrylate nanoparticles after intravenous injection in rats", J. Pharm. Sci. 1984, 73, 1433-1437.

61. O’Mullane, J. E.; Petrak, K.; Hutchinson, L. E. F.; Tomlinson, E. "The effect of adsorbed coats of Poloxamers 237 and 338 on the in vitro aggregation and in vivo distribution of polystyrene latex (PSL) particles", Int. J. Pharm. 1990, 63, 177-180.

62. Watrous-Peltier, N.; Uhl, J.; Steel, V.; Brophy, L.; Merisko-Liversidge, E. "Direct suppresion of phagocytosis by amphipathic polymeric surfactants", Pharm. Res. 1992, 9, 1177-1183. 
63. Tröster, S. D.; Müller, U.; Kreuter, J. "Modification of the body distribution of poly(methyl methacrylate) nanoparticles in rats by coating with surfactants", Int. J. Pharm. 1990, 61, 85-100.

64. Jain, D.; Athawale, R.; Bajaj, A.; Shrikhande, S.; Goel, P. N.; Gude, R. P. "Studies on stabilization mechanism and stealth effect of poloxamer 188 onto PLGA nanoparticles", Colloid Surface B 2013, 109, 59-67.

65. Gaymalov, Z. Z.; Yang, Z.; Pisarev, V. M.; Alakhov, V. U.; Kabanov, A. V. "The Effect of the Nonionic Block Copolymer Pluronic P85 on Gene Expression in Mouse Muscle and Antigen Presenting Cells", Biomaterials 2009, 30, 1232-1245.

66. Moghimi, S. M.; Hawley, A. E.; Christy, N. M.; Gray, T.; Illum, L; Davis, S. S. "Surface engineered nanospheres with enhanced drainage into lymphatics and uptake by macrophages of the regional lymph nodes", FEBS Lett. 1994, 344, 25-30.

67. Hawley, A. E.; Illum, L.; Davis, S. S. "Lymph node localisation of biodegradable nanospheres surface modified with poloxamer and poloxamine block co-polymers", FEBS Lett. 1997, 400, 319-323.

68. Sanjula, B.; Shah, F. M.; Javed, A.; Alka, A. "Effect of poloxamer 188 on lymphatic uptake of carvedilol-loaded solid lipid nanoparticles for bioavailability enhancement", $J$. Drug Target. 2009, 17, 249-256.

69. Porter, C. J. H.; Moghimi, S. M.; Illum, L.; Davis, S. S. "The polyoxyethylene/polyoxypropylene block co-polymer Poloxamer-407 selectively redirects intravenously injected microspheres to sinusoidal endothelial cells of rabbit bone marrow", FEBS Lett. 1992, 305, 62-66. 
70. Ratzinger, G.; Langer, U.; Neutsch, L.; Pittner, F.; Wirth, M.; Gabor, F. "Surface modification of PLGA particles: the interplay between stabilizer, ligand size, and hydrophobic interactions", Langmuir 2010, 26, 1855-1859.

71. de Gennes, P. G. "Polymers at an interface; a simplified view", Adv. Colloid Interfac. 1987, 27, 189-209.

72. Santander-Ortega, M. J.; Jodar-Reyes, A. B.; Csaba, N.; Bastos-Gonzalez, D.; OrtegaVinuesa, J. L. "Colloidal stability of pluronic F68-coated PLGA nanoparticles: a variety of stabilisation mechanisms", J. Colloid Interf. Sci. 2006, 302, 522-529.

73. Illum, L.; Jacobsen, L. O.; Muller, R. H.; Mak, E.; Davis, S. S. "Surface characteristics and the interaction of colloidal particles with mouse peritoneal macrophages", Biomaterials 1987, 8, 113-117.

74. Kayes, J. B.; Rawlins, D. A. "Adsorption characteristics of certain polyoxyethylenepolyoxypropylene block co-polymers on polystyrene latex", Colloid Polym. Sci. 1979, $257,622-629$.

75. Tadros, T. F.; Vincent, B. "Influence of temperature and electrolytes on the adsorption of poly(ethylene oxide)-poly(propylene oxide) block copolymer on polystyrene latex and on the stability of the polymer-coated particles", J. Phys. Chem. $1980,84,1575-1580$.

76. Baker, J. A.; Berg, J. C. "Investigation of the adsorption configuration of polyethylene oxide and its copolymers with polypropylene oxide on model polystyrene latex dispersions", Langmuir 1988, 4, 1055-1061. 
77. Jódar-Reyes, A. B.; Ortega-Vinuesa, J. L.; Martín-Rodríguez, A.; Leermakers, F. A. M. "Modeling the Effect of Structural Details of Nonionic Surfactants on Micellization in Solution and Adsorption onto Hydrophobic Surfaces", Langmuir 2002, 18, 8706-8713.

78. Jódar-Reyes, A. B.; Ortega-Vinuesa, J. L.; Martín-Rodríguez, A.; Leermakers, F. A. M. "Self-Consistent Field Model of Inhomogeneous Adsorption of Nonionic Surfactants onto Polystyrene Latex", Langmuir 2003, 19, 878-887.

79. Stolnik, S.; Daudali, B.; Arien, A.; Whetstone, J.; Heald, C. R.; Garnett, M. C.; Davis, S. S.;Illum, L. "The effect of surface coverage and conformation of poly(ethylene oxide) (PEO) chains of poloxamer 407 on the biological fate of model colloidal drug carriers", Biochim. Biophys. Acta 2001, 1514, 261-279.

80. Stolnik, S.; Felumb, N. C.; Heald, C. R.; Garnett, M. C.; Illum, L.; Davis, S. S. "Adsorption behaviour and conformation of selected poly(ethylene oxide) copolymers on the surface of a model colloidal drug carrier", Colloid Surface A 1997, 122, 151-159.

81. Faers, M. A.; Luckham, P. F. "Rheology of polyethylene oxide-polypropylene oxide block copolymer stabilized latices and emulsions", Colloid. Surface A. 1994, 86, 317327.

82. Greenwood, R.; Luckham, P. F.; Gregory, T. "The effect of particle size on the layer thickness of a stabilising polymer adsorbed onto two different classes of polymer latex, as determined from rheological experiments", Colloid Surface A 1995, 98, 117-125.

83. Zou, W.;Liu, C.; Chen, Z.;Zhang, N. "Studies on bioadhesive PLGA nanoparticles: A promising gene delivery system for efficient gene therapy to lung cancer", Int. J. Pharm. 2009, 370, 187-195. 
84. Owens, D. E., 3rd;Peppas, N. A. "Opsonization, biodistribution, and pharmacokinetics of polymeric nanoparticles", Int. J. Pharm. 2006, 307, 93-102.

85. Plard, J.-P.; Bazile, D. "Comparison of the safety profiles of PLA50 and Me.PEGPLA50 nanoparticles after single dose intravenous administration to rat", Colloid Surface $B$ 1999, 16, 173-183.

86. Illum, L.; Hunneyball, I. M.; Davis, S. S. "The effect of hydrophilic coatings on the uptake of colloidal particles by the liver and by peritoneal macrophages", Int. J. Pharm. $1986,29,53-65$.

87. Illum, L.; Davis, S. S. "The organ uptake of intravenously administered colloidal particles can be altered using a non-ionic surfactant (Poloxamer 338)", FEBS lett. 1984, 167, 79-82.

88. Norde, W.; Lyklema, J. "Thermodynamics of protein adsorption. Theory with special reference to the adsorption of human plasma albumin and bovine pancreas ribonuclease at polystyrene surfaces", J. Colloid Interf. Sci. 1979, 71, 350-366.

89. Rudt, S.; Müller, R. H. "In vitro phagocytosis assay of nano- and microparticles by chemiluminescence. II. Effect of surface modification by coating of particles with poloxamer on the phagocytic uptake", J. Control. Release 1993, 25, 51-59.

90. Semete, B.; Booysen, L.; Kalombo, L.; Ramalapa, B.; Hayeshi, R.; Swai, H. S. "Effects of protein binding on the biodistribution of PEGylated PLGA nanoparticles post oral administration", Int. J. Pharm. 2012, 424, 115-120.

91. Semete, B.; Booysen, L.; Lemmer, Y.; Kalombo, L.; Katata, L.; Verschoor, J.; Swai, H. S. "In vivo evaluation of the biodistribution and safety of PLGA nanoparticles as drug delivery systems", Nanomedicine 2010, 6, 662-671. 
92. Stolnik, S.; Illum, L.; Davis, S. S. "Long circulating microparticulate drug carriers", Adv. Drug Deliver. Rev. 1995, 16, 195-214.

93. Chen, Y. C.; Hsieh, W. Y.; Lee, W. F.; Zeng, D. T. "Effects of surface modification of PLGA-PEG-PLGA nanoparticles on loperamide delivery efficiency across the bloodbrain barrier", J. Biomater. Appl. 2013, 27, 909-922.

94. Juliano, R. L. "Factors affecting the clearance kinetics and tissue distribution of liposomes, microspheres and emulsions", Adv. Drug Deliver. Rev. 1988, 2, 31-54.

95. Blasi, P.; Giovagnoli, S.; Schoubben, A.; Ricci, M.; Rossi, C. "Solid lipid nanoparticles for targeted brain drug delivery", Adv. Drug Deliver. Rev. 2007, 59, 454477.

96. Kreuter, J. "Nanoparticulate systems for brain delivery of drugs", Adv. Drug Deliver. Rev. 2001, 47, 65-81.

97. Kreuter, J. "Influence of the surface properties on nanoparticle-mediated transport of drugs to the brain", J. Nanosci. Nanotechnol. 2004, 4, 484-488.

98. Muller, R. H.; Gohla, S.; Keck, C. M. "State of the art of nanocrystals--special features, production, nanotoxicology aspects and intracellular delivery", Eur. J. Pharm. Biopharm. 2011, 78, 1-9.

99. Kreuter, J.; Gelperina, S. "Use of nanoparticles for cerebral cancer", Tumori 2008, 94, 271-277.

100. Gelperina, S.; Maksimenko, O.; Khalansky, A.; Vanchugova, L.; Shipulo, E.; Abbasova, K.; Berdiev, R.; Wohlfart, S.; Chepurnova, N.; Kreuter, J. "Drug delivery to the brain using surfactant-coated poly(lactide-co-glycolide) nanoparticles: Influence of the formulation parameters", Eur. J. Pharm. Biopharm. 2010, 74, 157-163. 
101. Steiniger, S. C. J.; Kreuter, J.; Khalansky, A. S.; Skidan, I. N.; Bobruskin, A. I.; Smirnova, Z. S.; Severin, S. E.; Uhl, R.; Kock, M.; Geiger, K. D.; Gelperina, S. E. "Chemotherapy of glioblastoma in rats using doxorubicin-loaded nanoparticles", Int. J. Cancer 2004, 109, 759-767.

102. Ambruosi, A.; Gelperina, S.; Khalansky, A.; Tanski, S.; Theisen, A.; Kreuter, J. "Influence of surfactants, polymer and doxorubicin loading on the anti-tumour effect of poly(butyl cyanoacrylate) nanoparticles in a rat glioma model", J. Microencapsul. 2006, $23,582-592$.

103. Petri, B.; Bootz, A.; Khalansky, A.; Hekmatara, T.; Muller, R.; Uhl, R.; Kreuter, J.; Gelperina, S. "Chemotherapy of brain tumour using doxorubicin bound to surfactantcoated poly(butyl cyanoacrylate) nanoparticles: revisiting the role of surfactants", $J$. Control. Release 2007, 117, 51-58.

104. Gulyaev, A.; Gelperina, S.; Skidan, I.; Antropov, A.; Kivman, G.; Kreuter, J. "Significant Transport of Doxorubicin into the Brain with Polysorbate 80-Coated Nanoparticles", Pharm. Res. 1999, 16, 1564-1569.

105. De Juan, B. S.; Von Briesen, H.; Gelperina, S. E.; Kreuter, J. "Cytotoxicity of doxorubicin bound to poly(butyl cyanoacrylate) nanoparticles in rat glioma cell lines using different assays", J.Drug Target. 2006, 14, 614-622.

106. Paillard-Giteau, A.; Tran, V. T.; Thomas, O.; Garric, X.; Coudane, J.; Marchal, S.;Chourpa, I.; Benoît, J. P.; Montero-Menei, C. N.; Venier-Julienne, M. C. "Effect of various additives and polymers on lysozyme release from PLGA microspheres prepared by an s/o/w emulsion technique", Eur. J. Pharm. Biopharm. 2010, 75, 128-136. 
107. Killmann, E.; Maier, H.; Baker, J. A. "Hydrodynamic layer thicknesses of various adsorbed polymers on precipitated silica and polystyrene latex", Colloid Surface 1988, $31,51-71$

108. Bevan, M. A.; Prieve, D. C. "Forces and Hydrodynamic Interactions between Polystyrene Surfaces with Adsorbed PEO-PPO-PEO", Langmuir 2000, 16, 9274-9281.

109. Holland, S. J.; Tighe, B. J.; Goulg, P. L. "Polymers for biodegradable medical devices: 1. The potential of polyesters as controlled macromolecular release systems", $J$. Control. Release 1986, 4, 155- 180.

110. Schliecker, G.; Schmidt, C.; Fuchs, S.; Ehinger, A.; Sandow, J.; Kisse, T. "In vitro and in vivo correlation of buserelin release from biodegradable implants using statistical moment analysis", J. Control. Release 2004, 94, 25- 37.

111. Higuchi, T. "Mechanisms of sustained action mediation. Theoretical analysis of rate of release of solid drugs dispersed in solid matrices", J. Pharm. Sci., 1963, 52, 11451149. 


\section{Legends of Figures}

Figure 1: Structure of poloxamer.

Figure 2: Schematic representation of poloxamer adsorption onto hydrophobic drug carrier surfaces: (a) PPO binds with carrier surface and PEO block extends to outer phase; (b) "brush-type" conformation and (c) "mushroom-type" conformation ${ }^{54}$.

Figure 3: Adsorption isotherms for P407 on PS NPs. Particle diameters: $40 \mathrm{~nm}(\diamond), 71 \mathrm{~nm}$ (匹) and 137nm (४) (Taken from Ref. 79, with permission from American Chemical Society, Copyright 2001).

Figure 4: Size distribution of uncoated PLGA and $(0.25 \%, 0.5 \%, 1 \%)$ poloxamer coated PLGA NPs.

Figure 5: (a) a negatively charged hydrophobic drug carrier PLGA NP (b) adsorption of a plasma protein e.g. HSA onto a PLGA NP.

Figure 6: (a) a poloxamer coated PLGA NP (b) prevention of protein adsorption onto a PLGA NP by poloxamer coating.

Figure 7: Relationship among thickness of the coating layer of poloxamers and poloxamine on PS particles and their relative phagocytic uptake by mouse peritoneal macrophages (Taken from Ref. 73, with permission from Elsevier, Copyright 1987).

Figure 8: Relative phagocytic uptake (AUC) of $3190 \mathrm{~nm}$ particles by human granulocytes coated with poloxamer polymers with increasing length of the PPO center part (22 different poloxamer) (Taken from Ref. 89, with permission from Elsevier, Copyright 1993).

41 
Figure 9: Biodistribution of Rhodamine labelled PLGA NPs. Days: (A) One; (B) Three; (C) Seven (after oral administration). (Taken from Ref. 90, with permission from Elsevier, Copyright 2012).

Figure 10: Schematic representation of the probable mechanism of surfactant coated NP's brain uptake. Drug releases from NPs upon endocytosis through the BBB endothelial cells.

Figure 11: Kaplan-Meier survival plot of rats with intracranially transplanted 101/8 glioblastoma after intravenous administration of doxorubicin formulations $(\mathrm{n}=10-12)$ (Taken from Ref. 100, with permission from Elsevier, Copyright 2010).

Figure 12: In vitro release profile of lysozyme from PLGA MPs without P188 $(\times)(n=2$ batches, twice) and with P188 $(\Delta)(\mathrm{n}=3$ batches $)$ and from PLGA-PEG-PLGA MPs containing P188 ( $\square$ ) ( $\mathrm{n}=7$ batches) (Taken from Ref. 106, with permission from Elsevier, Copyright 2010).

Figure 13: Curvature-dependent adlayer thickness for poloxamers (Taken from Ref. 54, with permission from American Chemical Society, Copyright 1994).

Figure 14: Relation among coated layer thickness and EO units for PS MPs. Coating agents: poloxamers and poloxamine (Taken from Ref. 73, with permission from Elsevier, Copyright 1987). 


\section{Legends of Tables}

Table1: Parameters of poloxamers which are discussed in this review.

Table 2: Adsorption pattern of P407 onto 40, 70 and $137 \mathrm{~nm}$ PS NPs ${ }^{79}$.

Table 3: Points of adsorption isotherm for P407 adsorption onto $40 \mathrm{~nm}$ PS NPs showing hydrodynamic layer thickness and others ${ }^{79}$.

Table 4: Thickness of adlayer for different poloxamers having different EO and PO units $^{73}$. 
Table_1: Some propertiesParameters of poloxamers (only those-which are discussed in this review).

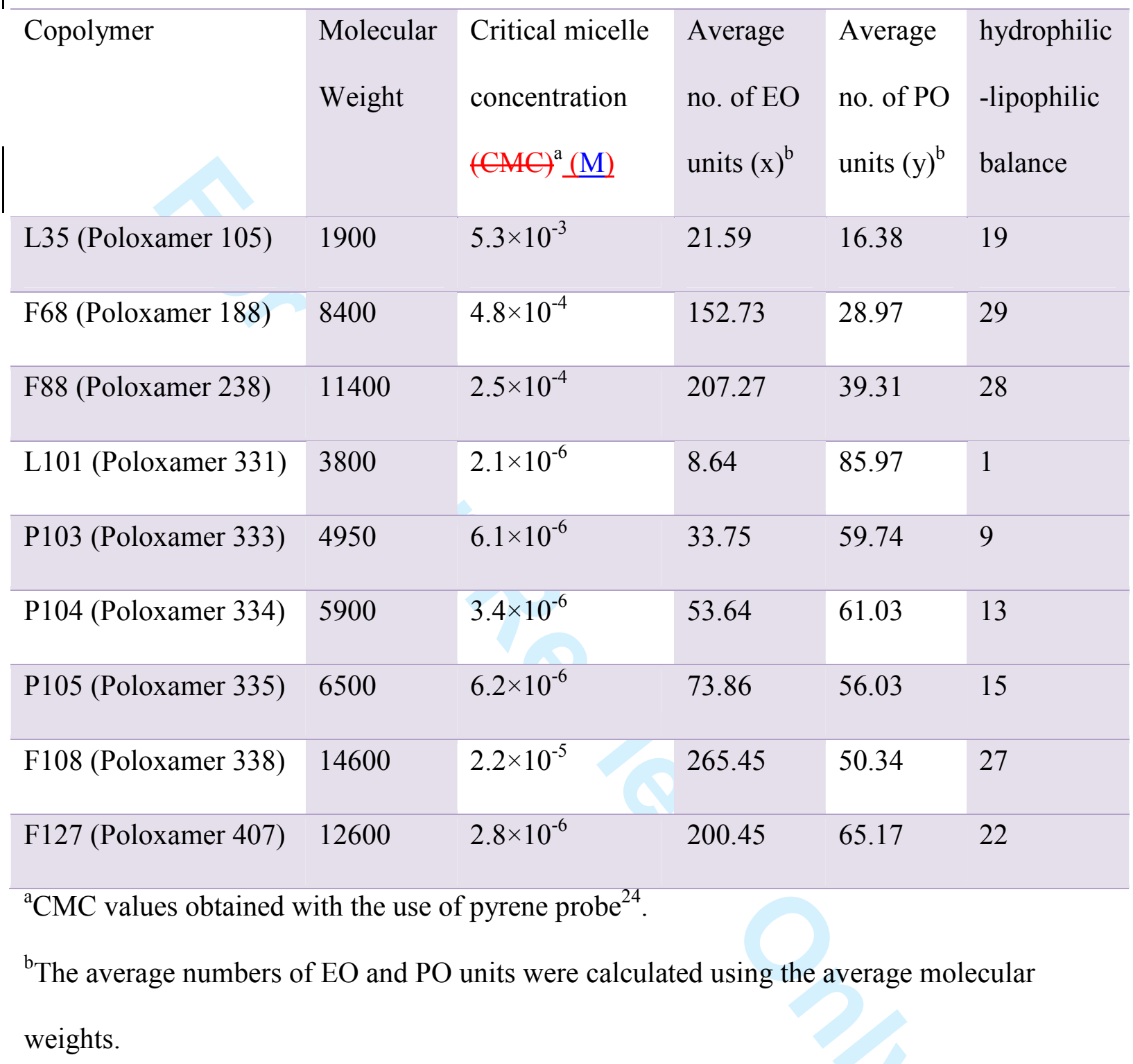


Table 2: Adsorption pattern of P407 onto 40, 70 and 137_nm PS NPs ${ }^{727}$.

\begin{tabular}{|c|c|c|c|}
\hline $\begin{array}{l}\text { Particle size } \\
(\mathrm{nm})\end{array}$ & $\begin{array}{l}\text { Average amount } \\
\text { adsorbed } \\
\left(\mu \mathrm{mol} / \mathrm{m}^{2}\right)\end{array}$ & $\begin{array}{l}\text { Average amount } \\
\text { adsorbed } \\
\left(\mathrm{mg} / \mathrm{m}^{2}\right)\end{array}$ & $\begin{array}{l}\text { Hydrodynamic } \\
\text { layer thickness } \\
(\mathrm{nm})\end{array}$ \\
\hline 137 & $0.19 \pm 0.02$ & $2.4 \pm 0.2$ & $7.7 \pm 0.5$ \\
\hline 70 & $0.16 \pm 0.04$ & $2.0 \pm 0.5$ & $7.7 \pm 0.3$ \\
\hline 40 & $0.18 \pm 0.03$ & $2.3 \pm 0.3$ & $8.5 \pm 0.1$ \\
\hline
\end{tabular}


Table 3: Points of adsorption isotherm for P407 adsorption onto 40nm PS NPs showing hydrodynamic layer thickness and others ${ }^{797}$.

\begin{tabular}{lllllll}
\hline $\begin{array}{l}\text { Amount } \\
\text { adsorbed }\end{array}$ & Amount & Hydrodynamic & Average & Average & Surface \\
$\left(\mathrm{mg} / \mathrm{m}^{2}\right)$ & $\left(\mathrm{nmol} / \mathrm{m}^{2}\right)$ & $(\mathrm{nm})$ & molecule & PEO chain & $(\%)$ \\
\hline 0.097 & 7.72 & 1.23 & $\left(\mathrm{~nm}^{2}\right)$ & $\left(\mathrm{nm}^{2}\right)$ & \\
\hline 0.23 & 18.3 & 1.33 & 215 & 107.5 & 4 \\
\hline 0.608 & 48.3 & 4.03 & 90.7 & 45.4 & 10 \\
\hline 0.869 & 69 & 6.22 & 34.4 & 17.2 & 26 \\
\hline 1.173 & 93.1 & 5.88 & 24.1 & 12 & 37 \\
\hline 1.1449 & 115 & 6 & 17.8 & 8.9 & 50 \\
\hline 2.293 & 182 & 8.32 & 14.4 & 7.2 & 63 \\
\hline
\end{tabular}


Table 4: Average size of PLGA NPs coated with poloxamer F68.

\begin{tabular}{lll}
\hline Percentage of poloxamer & Size $(\mathrm{nm})$ \\
\hline $0 \%($ control $)$ & 199.8 \\
\hline $0.25 \% \mathrm{~F} 68$ & 207.4 \\
\hline $0.5 \% \mathrm{~F} 68$ & 256.3 \\
\hline $1 \% \mathrm{~F} 68$ & 201.3 \\
\hline
\end{tabular}

Table 4: Thickness of adlayer for different poloxamers having different EO and PO units $^{73}$.

\begin{tabular}{|c|c|c|c|c|}
\hline \multirow{2}{*}{$\begin{array}{c}\text { Type of } \\
\text { poloxamer }\end{array}$} & \multicolumn{3}{|c|}{ Molecular block average values (mol) } & \multirow{2}{*}{$\begin{array}{l}\text { Thickness of } \\
\text { adlayer (nm) }\end{array}$} \\
\hline & $\underline{\mathrm{EO}}$ & $\underline{\mathrm{PO}}$ & $\underline{\mathrm{EO}}$ & \\
\hline P188 & 75 & $\underline{30}$ & 75 & 7.6 \\
\hline$\underline{\text { F88 }}$ & $\underline{97}$ & $\underline{39}$ & 97 & 13.2 \\
\hline P338 & 128 & $\underline{54}$ & $\underline{128}$ & 15.8 \\
\hline P407 & $\underline{98}$ & $\underline{67}$ & $\underline{98}$ & $\underline{15.4}$ \\
\hline
\end{tabular}




\section{Hydrophilic Hydrophobic
Figure 1 : Structure of poloxamer.
$189 \times 87 \mathrm{~mm}(96 \times 96 \mathrm{DPI})$ \\ Hydrophilic
Hydrophobic
Figure 1 : Structure of poloxamer
$189 \times 87 \mathrm{~mm}(96 \times 96 \mathrm{DPI})$}


Figure 2: Schematic representation of poloxamer adsorption onto hydrophobic drug carrier surfaces: (a) PPO binds with carrier surface and PEO block extends to outer phase; (b) "brush-type" conformation and (c) "mushroom-type" conformation54. $569 \times 179 \mathrm{~mm}(96 \times 96 \mathrm{DPI})$ 


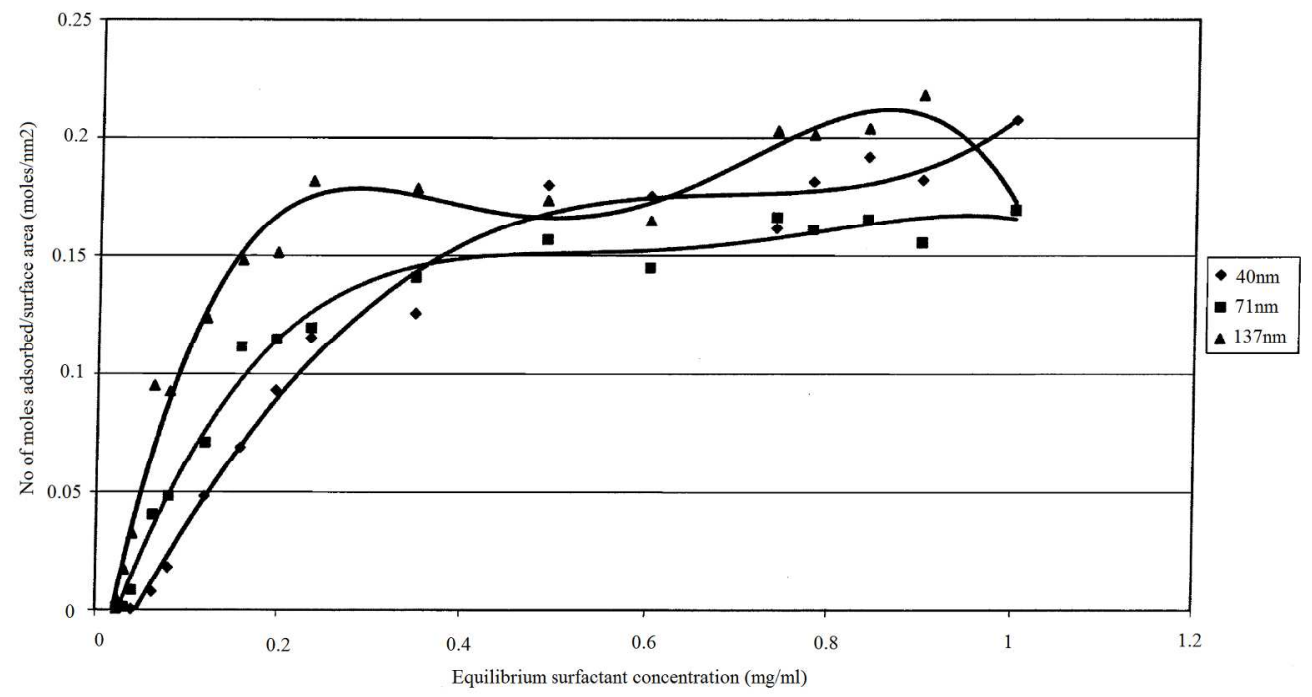

Figure 3: Adsorption isotherms for P407 on PS NPs. Particle diameters: $40 \mathrm{~nm}(\bullet), 71 \mathrm{~nm}(\boldsymbol{\bullet})$ and $137 \mathrm{~nm}(\boldsymbol{\Lambda})$ (Taken from Ref. 79, with permission from American Chemical Society, Copyright 2001). $552 \times 300 \mathrm{~mm}(96 \times 96$ DPI) 
Figure 4: Size distribution of uncoated PLGA and $(0.25 \%, 0.5 \%, 1 \%)$ poloxamer coated PLGA NPs. $411 \times 111 \mathrm{~mm}(96 \times 96 \mathrm{DPI})$ 


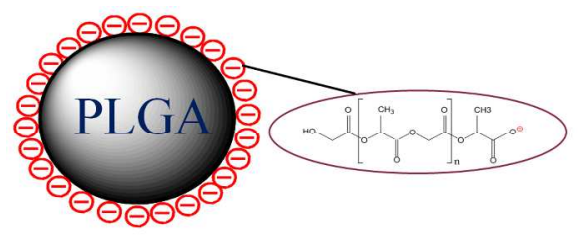

(a)

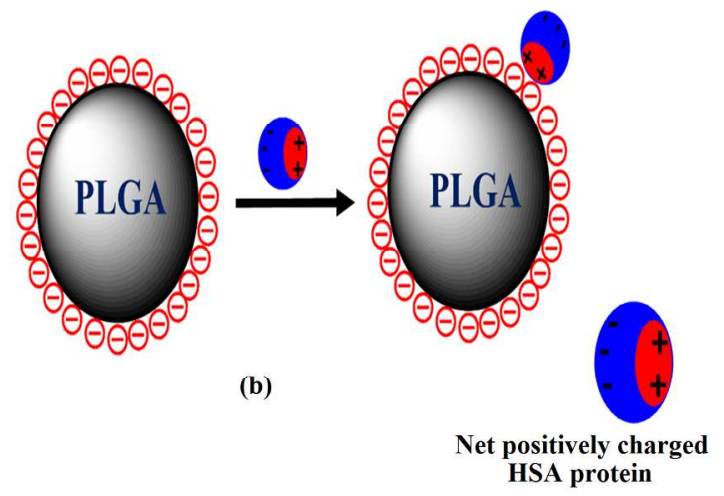

Figure 5: (a) a negatively charged hydrophobic drug carrier PLGA NP (b) adsorption of a plasma protein e.g. HSA onto a PLGA NP. $614 \times 240 \mathrm{~mm}(96 \times 96$ DPI $)$ 


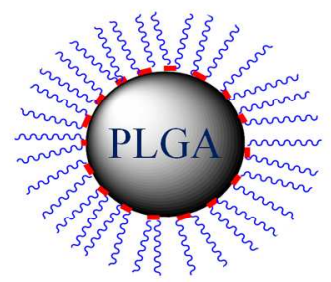

PEO block nurns PPO block

(a)

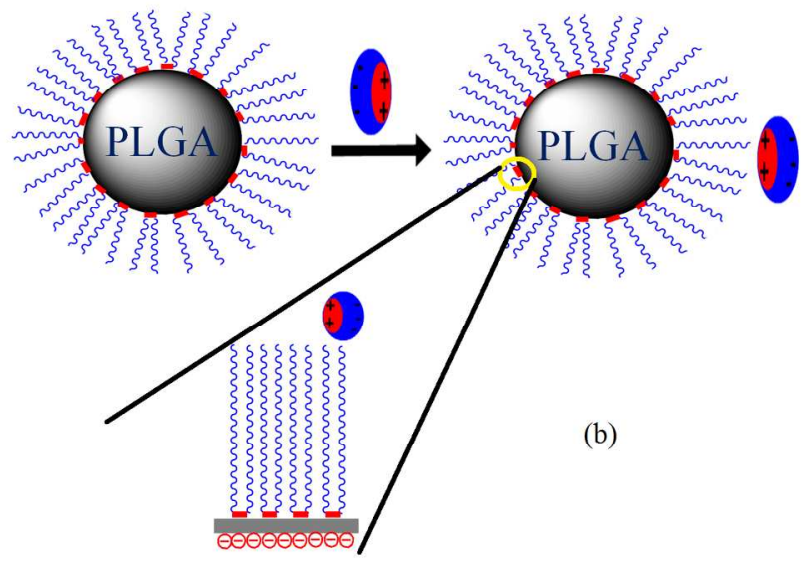

Figure 6: (a) a poloxamer coated PLGA NP (b) prevention of protein adsorption onto a PLGA NP by poloxamer coating. $569 \times 258 \mathrm{~mm}(96 \times 96$ DPI $)$ 
Figure 7: Relationship among thickness of the coating layer of poloxamers and poloxamine on PS particles and their relative phagocytic uptake by mouse peritoneal macrophages (Taken from Ref. 73, with permission from Elsevier, Copyright 1987). $390 \times 257 \mathrm{~mm}(96 \times 96 \mathrm{DPI})$ 


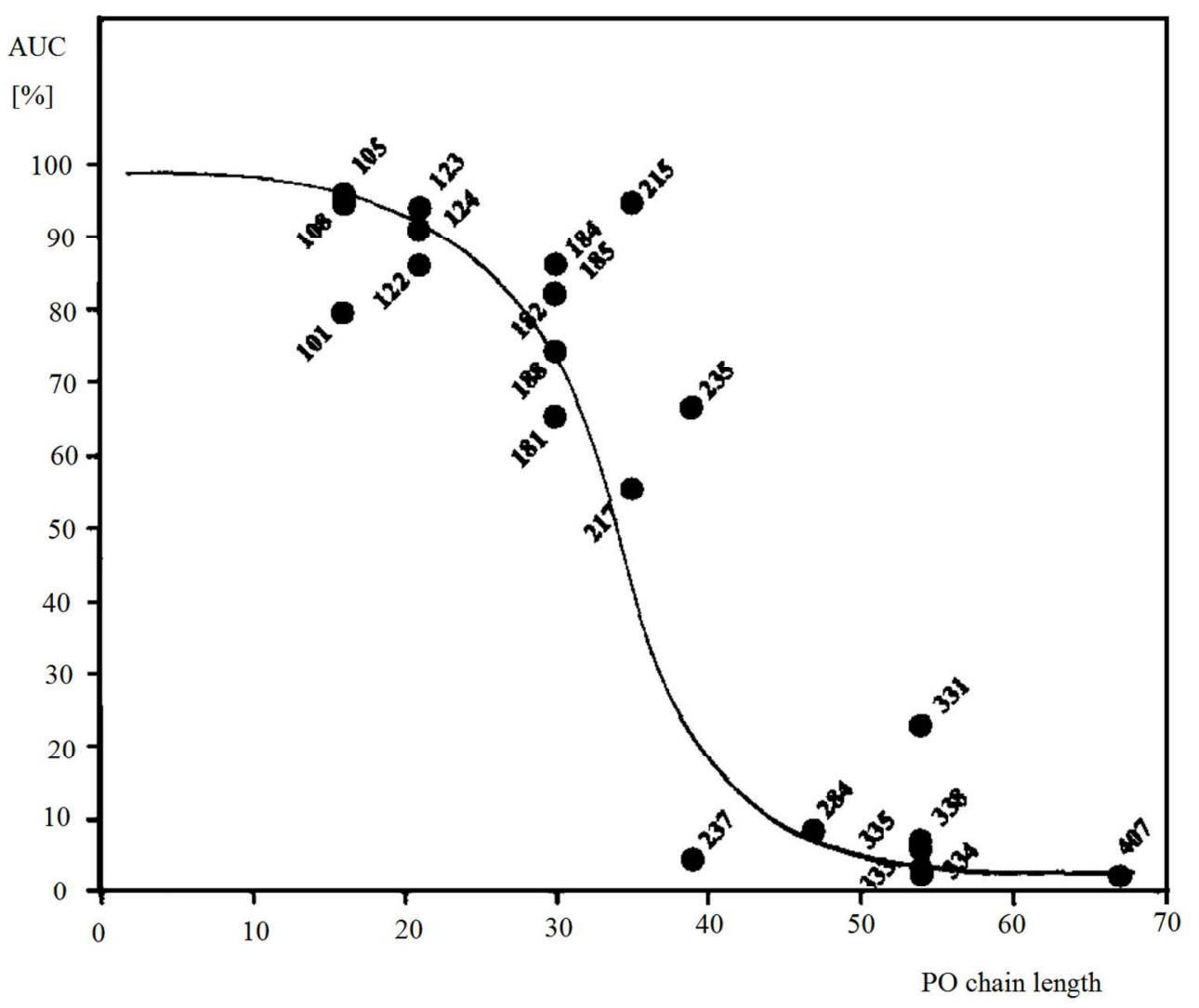

Figure 8: Relative phagocytic uptake (AUC) of $3190 \mathrm{~nm}$ particles by human granulocytes coated with poloxamer polymers with increasing length of the PPO center part (22 different poloxamer) (Taken from Ref. 89, with permission from Elsevier, Copyright 1993). $357 \times 306 \mathrm{~mm}(96 \times 96 \mathrm{DPI})$ 

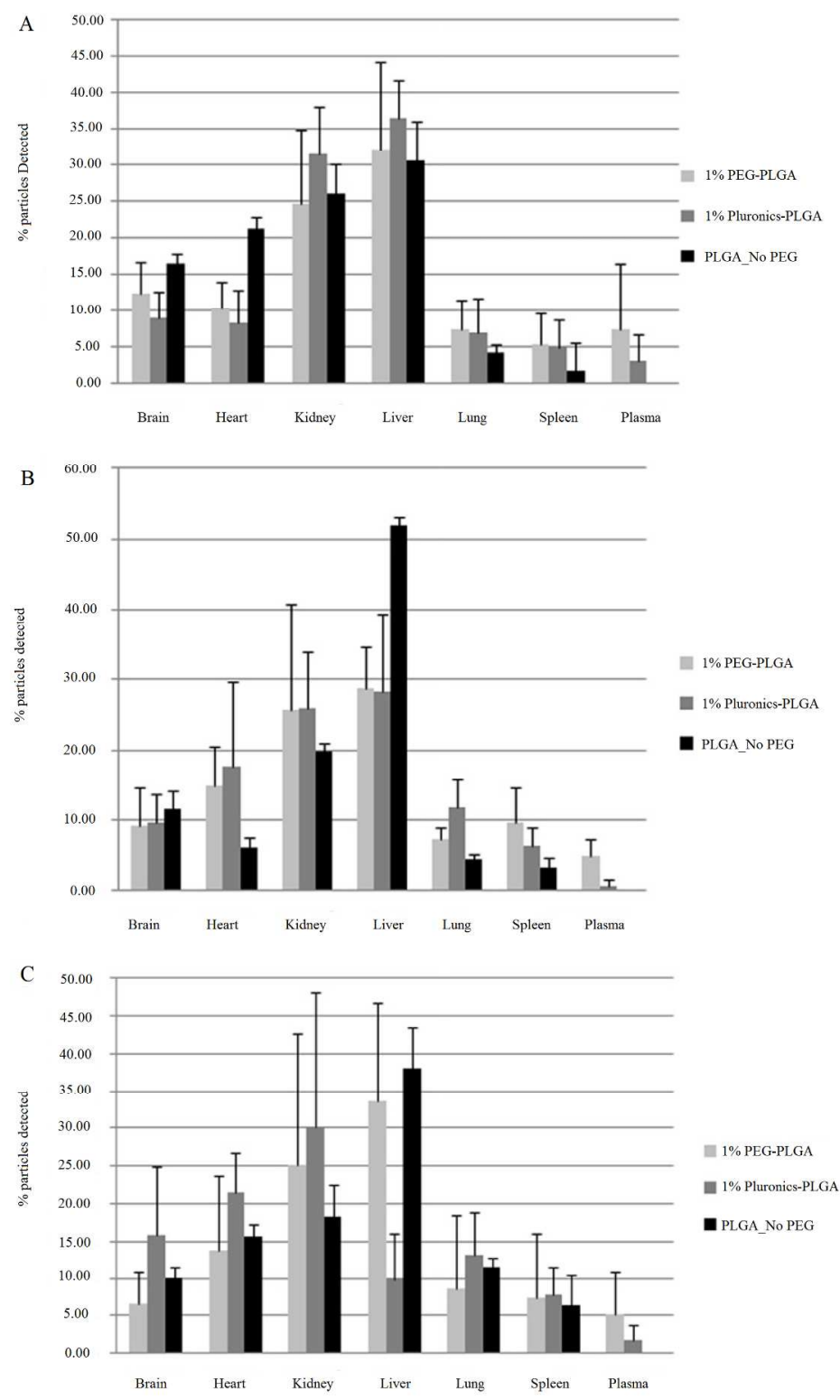

Figure 9: Biodistribution of Rhodamine labelled PLGA NPs. Days: (A) One; (B) Three; (C) Seven (after oral administration). (Taken from Ref. 90, with permission from Elsevier, Copyright 2012). $516 \times 829 \mathrm{~mm}$ (96 x 96 DPI) 
Figure 10: Schematic representation of the probable mechanism of surfactant coated NP's brain uptake. Drug releases from NPs upon endocytosis through the BBB endothelial cells. $973 \times 343 \mathrm{~mm}(96 \times 96 \mathrm{DPI})$ 
Figure 11: Kaplan-Meier survival plot of rats with intracranially transplanted 101/8 glioblastoma after intravenous administration of doxorubicin formulations $(n=10-12)$ (Taken from Ref. 100, with permission from Elsevier, Copyright 2010). $397 \times 294 \mathrm{~mm}(96 \times 96$ DPI) 


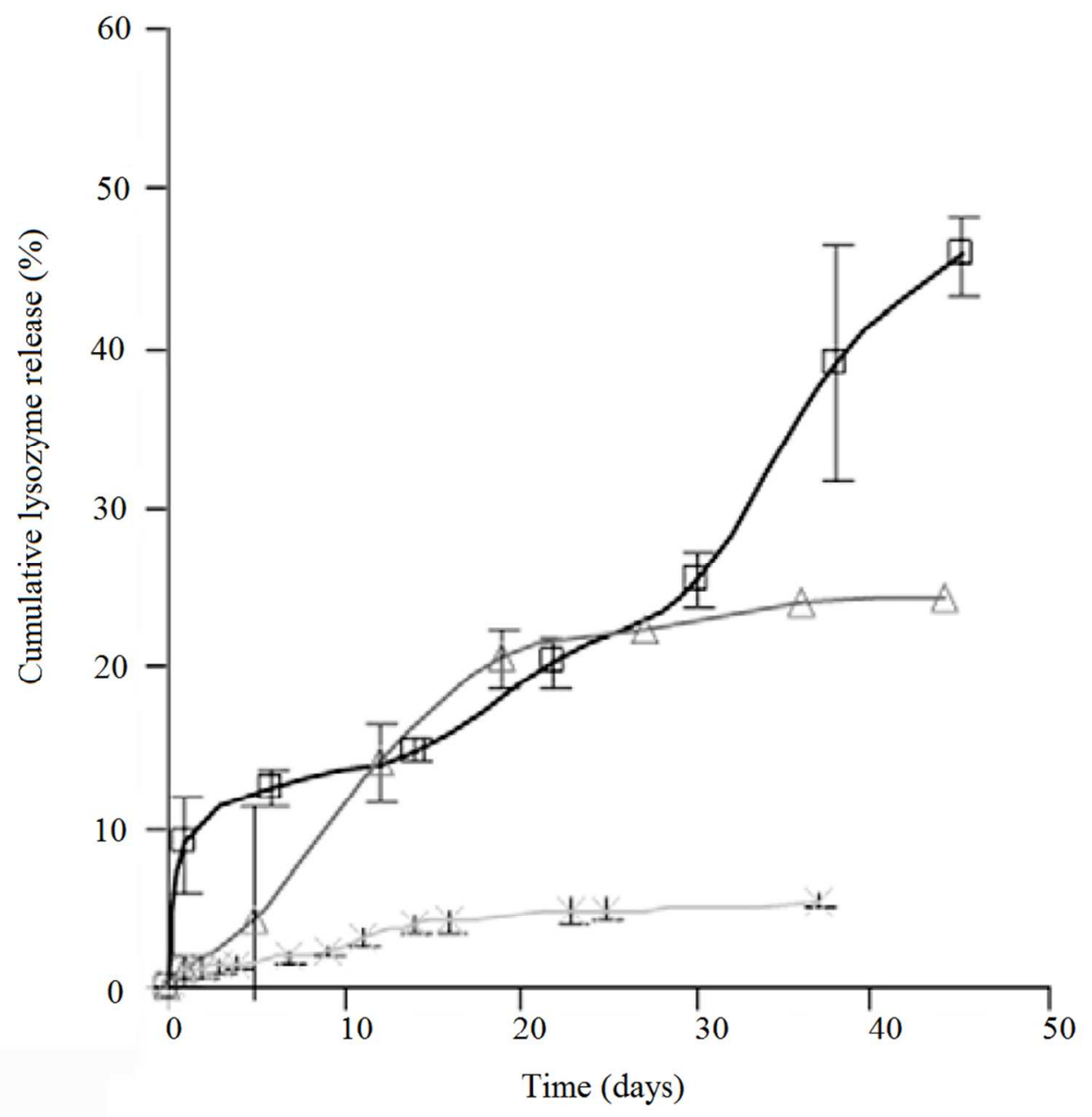

Figure 12: In vitro release profile of lysozyme from PLGA MPs without P188 $(x)(n=2$ batches, twice) and with P188 $(\Delta)(n=3$ batches) and from PLGA-PEG-PLGA MPs containing P188 ( $\square$ ) ( $n=7$ batches) (Taken from Ref. 106, with permission from Elsevier, Copyright 2010). $278 \times 285 \mathrm{~mm}$ (96 x 96 DPI) 


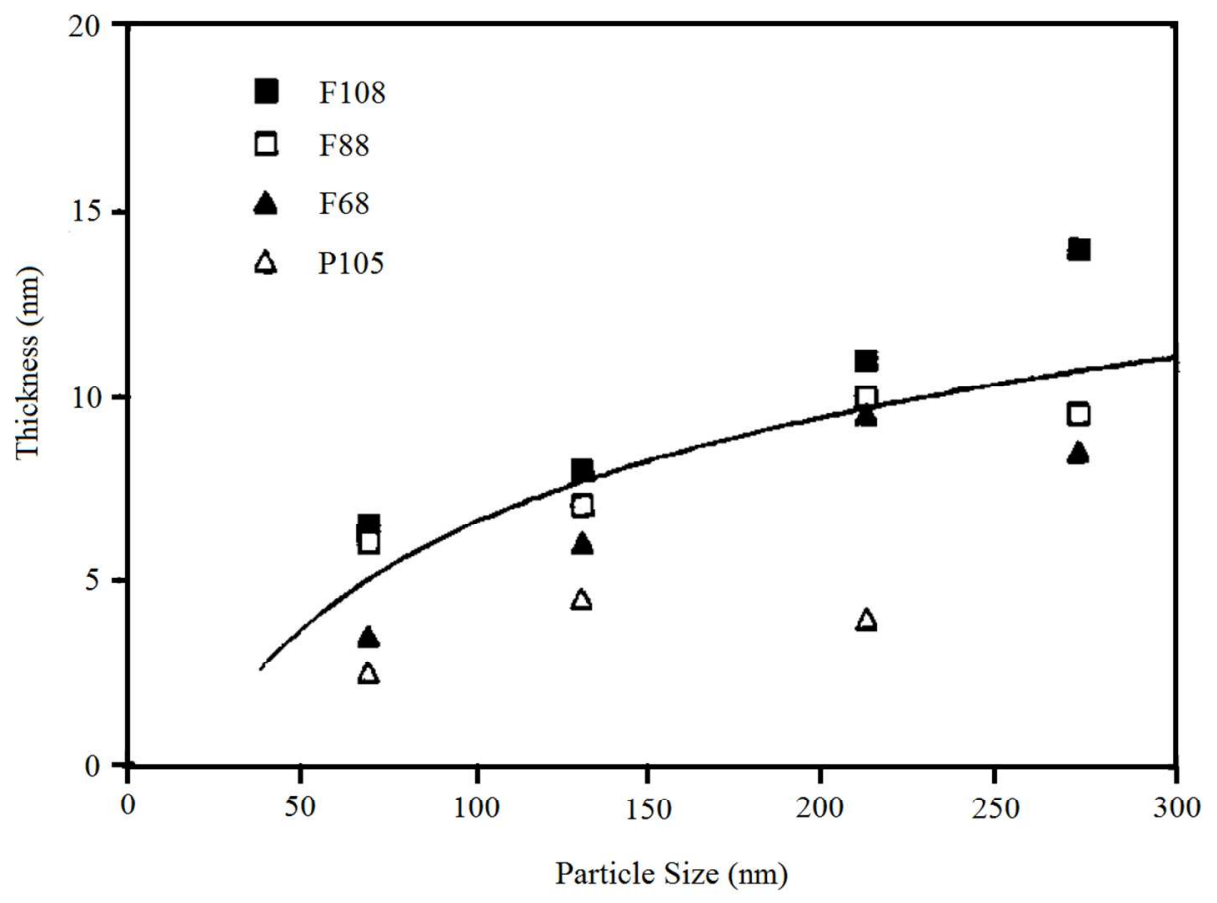

Figure 13: Curvature-dependent adlayer thickness for poloxamers (Taken from Ref. 54, with permission from American Chemical Society, Copyright 1994). $338 \times 251 \mathrm{~mm}(96 \times 96 \mathrm{DPI})$ 
Figure 14: Relation among coated layer thickness and EO units for PS MPs. Coating agents: poloxamers and poloxamine (Taken from Ref. 73, with permission from Elsevier, Copyright 1987). $411 \times 285 \mathrm{~mm}(96 \times 96 \mathrm{DPI})$ 